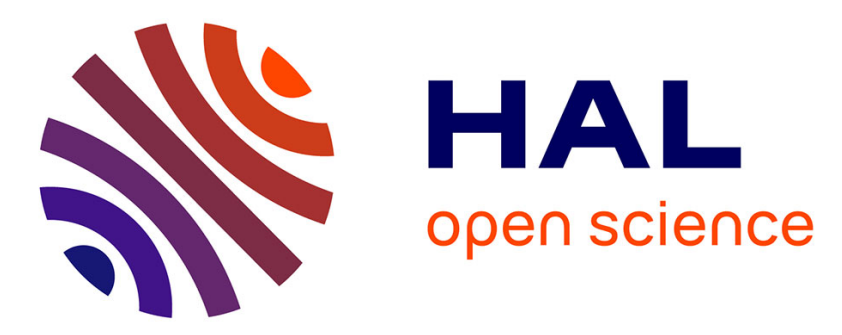

\title{
Basin-wide seasonal evolution of the Indian Ocean's phytoplankton blooms
}

\author{
Marina Lévy, D. Shankar, Jean-Michel André, S. S. C. Shenoi, Fabien \\ Durand, Clément de Boyer Montégut
}

\section{- To cite this version:}

Marina Lévy, D. Shankar, Jean-Michel André, S. S. C. Shenoi, Fabien Durand, et al.. Basin-wide seasonal evolution of the Indian Ocean's phytoplankton blooms. Journal of Geophysical Research, 2007, 112 (C12), pp.C12014. 10.1029/2007JC004090 . hal-00406743

\section{HAL Id: hal-00406743 \\ https://hal.science/hal-00406743}

Submitted on 2 Apr 2021

HAL is a multi-disciplinary open access archive for the deposit and dissemination of scientific research documents, whether they are published or not. The documents may come from teaching and research institutions in France or abroad, or from public or private research centers.
L'archive ouverte pluridisciplinaire HAL, est destinée au dépôt et à la diffusion de documents scientifiques de niveau recherche, publiés ou non, émanant des établissements d'enseignement et de recherche français ou étrangers, des laboratoires publics ou privés. 


\title{
Basin-wide seasonal evolution of the Indian Ocean's phytoplankton blooms
}

\author{
M. Lévy, ${ }^{1,2}$ D. Shankar, ${ }^{2}$ J.-M. André, ${ }^{1,2}$ S. S. C. Shenoi, ${ }^{2}$ F. Durand, ${ }^{2,3}$ \\ and C. de Boyer Montégut ${ }^{4}$
}

Received 5 January 2007; revised 2 August 2007; accepted 5 September 2007; published 21 December 2007.

[1] A climatology of Sea-viewing Wide Field-of-View Sensor (SeaWiFS) chlorophyll data over the Indian Ocean is used to examine the bloom variability patterns, identifying spatio-temporal contrasts in bloom appearance and intensity and relating them to the variability of the physical environment. The near-surface ocean dynamics is assessed using an ocean general circulation model (OGCM). It is found that over a large part of the basin, the seasonal cycle of phytoplankton is characterized by two consecutive blooms, one during the summer monsoon, and the other during the winter monsoon. Each bloom is described by means of two parameters, the timing of the bloom onset and the cumulated increase in chlorophyll during the bloom. This yields a regional image of the influence of the two monsoons on phytoplankton, with distinct regions emerging in summer and in winter. By comparing the bloom patterns with dynamical features derived from the OGCM (horizontal and vertical velocities and mixed-layer depth), it is shown that the regional structure of the blooms is intimately linked with the horizontal and vertical circulations forced by the monsoons. Moreover, this comparison permits the assessment of some of the physical mechanisms that drive the bloom patterns, and points out the regions where these mechanisms need to be further investigated. A new outcome of this study is that in many distinct areas, time shifts of 1-2 months are witnessed in the timing of the bloom onsets in adjoining regions. These time shifts are rationalized in terms of horizontal advection and Rossby wave propagation.

Citation: Lévy, M., D. Shankar, J.-M. André, S. S. C. Shenoi, F. Durand, and C. de Boyer Montégut (2007), Basin-wide seasonal evolution of the Indian Ocean's phytoplankton blooms, J. Geophys. Res., 112, C12014, doi:10.1029/2007JC004090.

\section{Introduction}

[2] A unique characteristic of the North Indian Ocean is that the seasonal cycle of phytoplankton is characterized by two growth periods. The most singular occurs in summer, the other in winter [e.g., Banse, 1987]. This contrasts with seasonal cycles in most part of the ocean, where phytoplankton bloom in winter-spring, production relaxes toward oligotrophy in summer and in some locations a fall bloom develops.

[3] It is now fairly well established that these two distinct periods of elevated biological activity result from the semiannual wind reversals associated with the monsoon system [Wiggert et al., 2005, 2006]. Over the North Indian

\footnotetext{
${ }^{1}$ Laboratoire d'Océanographie et du Climat: Expérimentation et Approches Numériques, IPSL, Paris, France.

${ }^{2}$ National Institute of Oceanography, Dona Paula, Goa, India.

${ }^{3}$ Laboratoire d'Etudes en Géophysique et Océanographie Spatiales, Toulouse, France.

${ }^{4}$ Frontier Research Center for Global Change, JAMSTEC, Yokohama, Japan.

Copyright 2007 by the American Geophysical Union. 0148-0227/07/2007JC004090
}

Ocean (north of $10^{\circ} \mathrm{S}$ ), winds generally blow from the southwest during the summer monsoon and from the northeast during the winter monsoon. These seasonally reversing winds force a seasonally reversing circulation in the upper ocean [Schott and McCreary, 2001; Shankar et al., 2002]. Monsoon winds also cause vertical mixing and produce coastal and open ocean upwelling and downwelling [Lee et al., 2000; Schott and McCreary, 2001]. This complex physical framework drives a pronounced basinwide spatio-temporal variability in the physical factors affecting productivity, i.e., the surface delivery of limiting nutrients and the mixed-layer depth. It results in phytoplankton blooms with a large variety in seasonal cycles [Banse and McClain, 1986; Banse and English, 2000; Murtugudde et al., 1999; Lierheimer and Banse, 2002; Vinayachandran and Mathew, 2003; Vinayachandran et al., 2004; Banzon et al., 2004; Wiggert et al., 2005].

[4] The aim of this paper is to advance the understanding of the patterns of phytoplankton seasonality in the Indian Ocean and to comment on the driving physical mechanisms. To achieve this goal, we developed a method for identifying the blooms over the Indian Ocean, which we applied to a climatology of surface chlorophyll (SCHL) constructed from 7 years of Sea-viewing Wide Field-of-view Sensor 


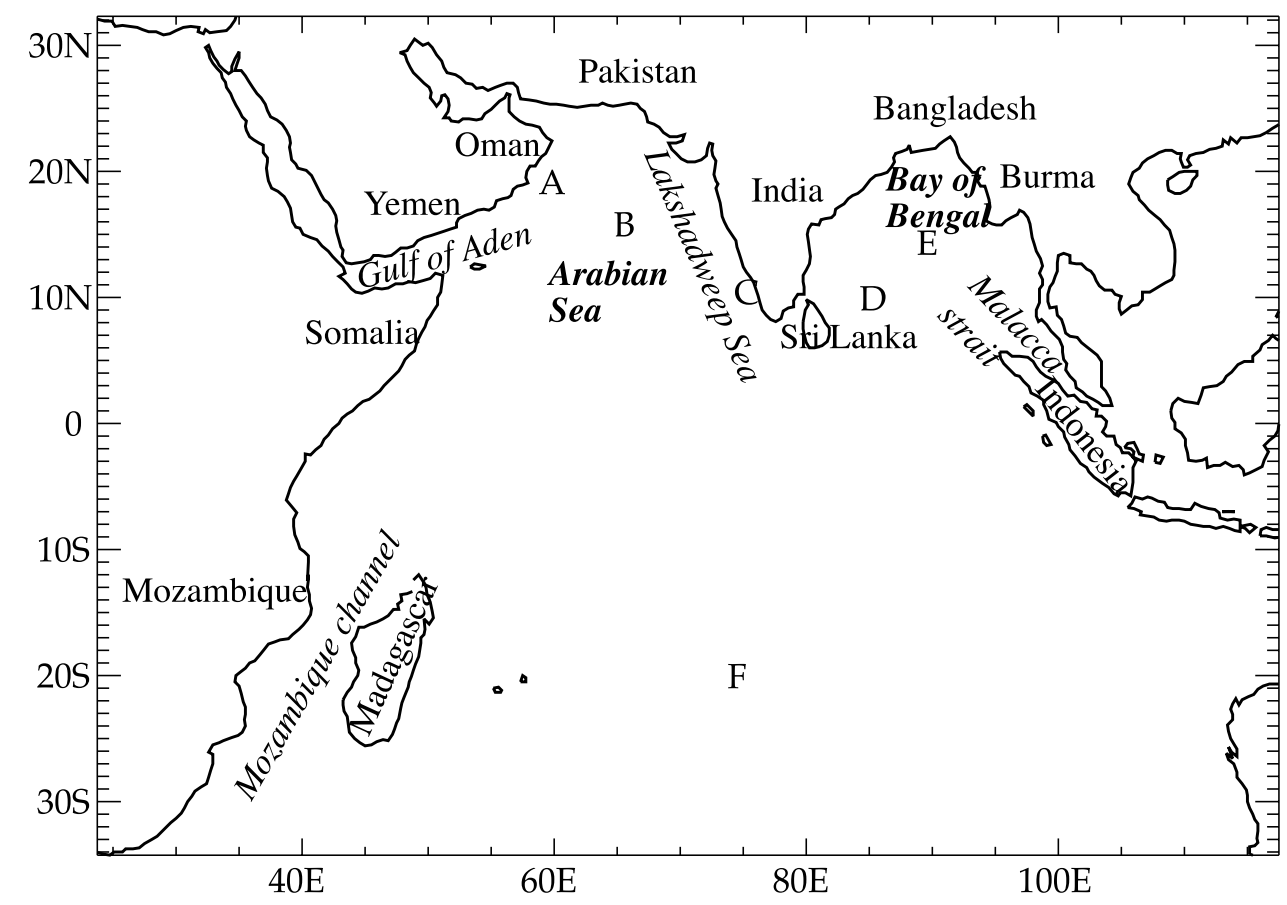

Figure 1. Map of the Indian Ocean and the adjacent landmass, showing the geographical locations referred to in the text. Letters A to F show the location of the six stations in Figure 2.

(SeaWiFS) data. The principle of the method is to distinguish the winter and the summer blooms, and to describe each bloom by means of two parameters: the timing of the bloom onset, and the increase in chlorophyll from the onset of the bloom until the peak of the bloom. The method is based on the reasonable hypothesis that physical processes impact the bloom during its onset stage, while biological processes become predominant as the bloom progresses. One of the underlying assumptions is that the onsets of blooms are associated with changes in the physical environment, like, for example, with the onset of a strong upwelling. On the other hand, the peak of the bloom marks the time when phytoplankton growth (through photosynthesis) and sinks (through mortality or grazing) equilibrate; hence, the peak is less related to the physical forcing. Following this idea, the originality of the method is that it gives emphasis to the period of the bloom onset, and takes into account the nonsynopticity of the different blooms at the scale of a few hundred kilometers. This contrasts with the previous studies that have examined sea color in the Indian Ocean [e.g., Wiggert et al., 2005], where more emphasis is given to the peak phase of the bloom.

[5] This analysis of SCHL climatology is complemented by cross comparison with near-surface ocean dynamics assessed from an Ocean General Circulation Model (OGCM). This comparison guides the interpretation of the blooms in terms of physical forcing mechanisms (upwelling, vertical mixing, horizontal advection) and is used as a cross validation for the identification of biophysical provinces.

[6] The main outcome of the paper is a comprehensive description of the phytoplankton seasonal cycles in the Indian Ocean, from $30^{\circ} \mathrm{N}$ to $30^{\circ} \mathrm{S}$ (Figure 1), in terms of the characteristics of the summer and winter blooms (timing, duration, intensity, mechanism).

\section{Data and Method}

\subsection{SeaWiFS Climatology}

[7] Level 3 standard-processed 8-days $9 \times 9 \mathrm{~km}$ SeaWiFS surface chlorophyll were used as a proxy for the phytoplankton content in the mixed layer. We constructed a climatology out of 7 years (April 1998 to March 2005) of data. Note that the first months of available SeaWiFS data (November 1997 to April 1998) were not used in this climatology because they contained large SCHL anomalies associated with the strong 1997-1998 El Niño/La Niña event [Murtugudde et al., 1999; Susanto and Marra, 2005].

[8] The main shortcoming of the standard-processed SeaWiFS data set is that it contains extensive data gaps, especially over the north Arabian Sea for a good part of the summer monsoon [Banzon et al., 2004]. This is due to cloudiness and to dust storms in the region from June to August, precluding good satellite-derived chlorophyll retrievals. Nevertheless, we found that, given our scales of interest, we could interpolate reasonably over the missing data (in space and time). The details of the construction of the climatology are provided by Lévy et al. [2006]. Lowpass space and time filters were applied to individual years before averaging. The final step was the degradation of the initial spatial resolution of the data to the model resolution $\left(0.5^{\circ} \times 0.5^{\circ}\right)$. Recently, the processing of SeaWiFS images with a Spectral Matching Algorithm (SMA) using a suite of Saharan dust models has been shown to significantly improve the data retrieval over the north Arabian Sea in summer [Banzon et al., 2004]. Our interpolated climatology shows summer SCHL patterns similar to those retrieved for 


\section{SCHL}

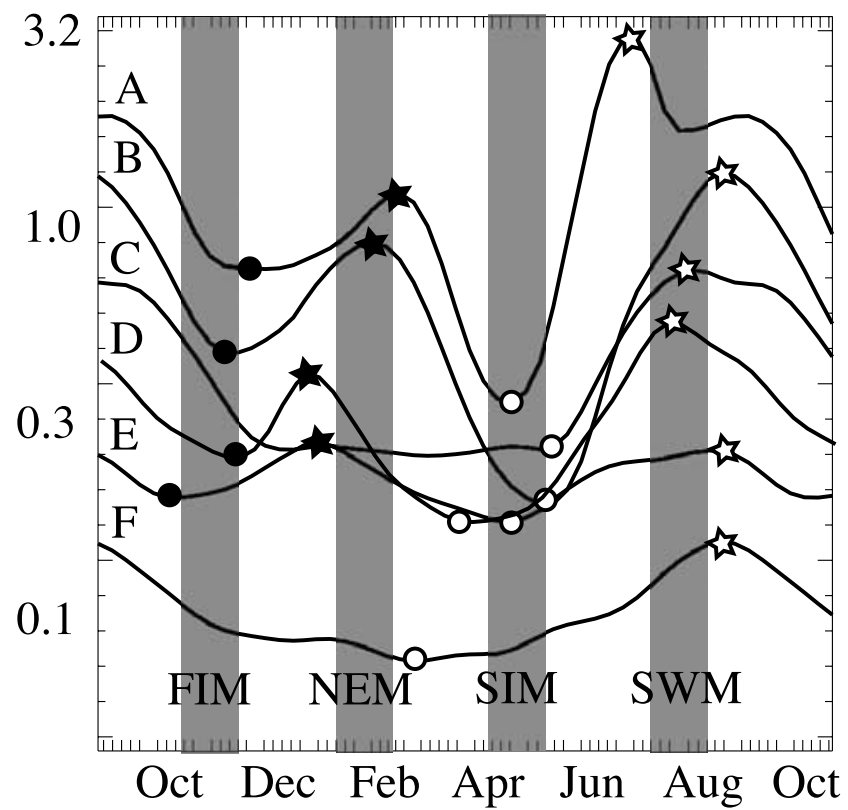

Figure 2. Examples of surface chlorophyll seasonal cycles at six stations (A to $\mathrm{F}$ ) in the Indian Ocean, in $\mathrm{mg} \mathrm{Chl} / \mathrm{m}^{3}$. Note that the ordinate is in log scale. The location of the stations is shown in Figure 1. Data are from a climatology constructed from 7 years (1998-2006) of SeaWiFS data. Bloom onset timings $\left(t_{\min }\right)$ are marked with circles, and bloom peak timings $\left(t_{\max }\right)$ are marked with stars. Open symbols are used for blooms peaking during the second part of the year (summer blooms, $t_{\min }^{\text {sum }}$ and $t_{\max }^{\text {sum }}$ ), and solid symbols are used for blooms peaking during the first part of the year (winter blooms, $t_{\text {min }}^{\text {win }}$ and $t_{\text {max }}^{\text {win }}$ ). The grey stripes mark the months most representative of the Fall Inter Monsoon (FIM), winter North East Monsoon (NEM), Spring Inter Monsoon (SIM), and summer South West Monsoon (SWM) periods.

2000 using the SMA [Banzon et al., 2004, Figure 11; Lévy et al., 2006, Figure 4].

[9] The interpolated climatology is available online at http://www.nio.org. It is worth noting that the large-scale temporal and spatial averaging precludes the examination of the role of finescale events like filaments or eddies.

\subsection{Physical Model}

[10] We used outputs from the NEMO OGCM in its global configuration ORCA05 (http://www.loceanipsl.upmc.fr/NEMO). The model run that we used is an updated version of the simulation validated by de Boyer Montégut et al. [2007] over the North Indian Ocean. The model had $0.5^{\circ}$ horizontal resolution and $10 \mathrm{~m}$ vertical resolution in the upper $120 \mathrm{~m}$. Climatologies of ERS1-2 wind stress [Bentamy et al., 1996] and of CMAP precipitation flux [Xie and Arkin, 1997] were used to prescribe the momentum and precipitation fluxes. Heat and evaporation were diagnosed through bulk formulae using NCEP reanalysis [Kalnay et al., 1997] air temperature. Monthly values of river discharge [U.N. Education, Scientific and Cultural Organization, 1996] were also accounted for. The reader is referred to de Boyer Montégut et al. [2007] for more details on the model physics and on its forcing.

[11] We used the model outputs for 1993 to 2000 to construct a seasonal climatology. Extensive validation of the model revealed that it reproduces the observed patterns of the thermohaline structure of the upper North Indian Ocean. In particular, the mixed-layer depth variability compared fairly well with the observed climatology of de Boyer Montégut et al. [2004].

\subsection{Identification of the Blooms}

[12] Figure 2 shows six examples of SCHL seasonal cycles at various stations in the Indian Ocean (stations are shown in Figure 1). It highlights the large variety of these cycles in terms of the number of significant peaks (one or two), their timing, and their magnitude. The general pattern is that phytoplankton peak after the onset of the summer and of the winter monsoons, and are minimum during the intermonsoon periods in spring and in fall.

[13] Usually, for the Indian Ocean, the seasonal cycle of SCHL is described by means of monthly climatologies, typically for January/February, April/May, July/August, and October/November (grey stripes in Figure 2), which sample the monsoon and intermonsoon periods [McCreary et al., 1996; Wiggert et al., 2005, 2006]. While such monthly descriptions give a fairly good qualitative image of the most productive regions, they cannot account for temporal shifts between regions. Indeed, phytoplankton blooms over the Indian Ocean have different timings: for example, the SWM stripe in Figure 2 captures the growing phase of the bloom over stations $\mathrm{B}, \mathrm{E}$, and $\mathrm{F}$, the peak of the bloom over $\mathrm{C}$ and $\mathrm{E}$, and the decay of the bloom over A. A second approach commonly used to describe the seasonal cycle of SCHL is to prescribe the coordinates of boxes (a few degrees wide), and to compute the time evolution of the mean SCHL values within each box [McCreary et al., 1996; Banse and English, 2000; Lierheimer and Banse, 2002]. This second approach is best suited to identify temporal shifts, but can hardly be used to identify regional characteristics since the boxes are chosen a priori.

[14] The method that we present here allows for a quantitative and regional description of the SCHL cycles in the Indian Ocean. Owing to the general bimodality of the seasonal cycle, the method distinguishes between the two blooms. From the perspective of biophysical coupling, two parameters are important for each bloom.

[15] The first parameter is the bloom onset time $\left(t_{\min }\right.$, circles in Figure 2). This parameter is crucial: it indicates when the ocean physics become active in driving the biology, for instance by providing nutrients to the euphotic layer. By definition, $t_{\min }$ is the time when SCHL starts increasing; we determined it as the time when SCHL is minimum. Similarly, we defined $t_{\max }$ as the time of the bloom peak (SCHL maximum, stars in Figure 2). In each pixel, the bloom period was defined as the time interval $t_{\min }$ to $t_{\max }$.

[16] The second important parameter is the cumulated increase in chlorophyll (CIC), which measures the integral of the increase in SCHL during the bloom period (in

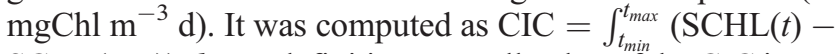
$\left.\operatorname{SCHL}\left(t_{\min }\right)\right) d t$. By definition, a small value of the CIC is not necessarily associated with low SCHL, but could also be due 
to either low SCHL increase or to a slow rate of increase. In cases where SCHL growth is essentially nutrient limited, the CIC provides a measure of the strength of phytoplankton growth mediated by the physical transport of nutrients. This is of course not exactly true, particularly as we approach the peak of the bloom or when SCHL remains more or less constant, as in such cases, phytoplankton growth and losses balance each other.

[17] In the following, we refer to "summer blooms" for blooms that peak between 15 May and 15 November (open symbols in Figure 2), and to "winter blooms" for blooms that peak between 15 November and 15 May (solid symbols in Figure 2). Note that these time intervals taken together cover the full year. Note also that the summer and winter monsoons only affect the Indian Ocean north of $10^{\circ} \mathrm{S}$; the notation, however, is convenient and is used for the entire basin. It implicitly refers to boreal summer and winter.

[18] In practice, in each location, our algorithm starts by searching $S C H L_{\max }^{\text {sum }}$ and $S C H L_{\max }^{\text {win }}$ (open and solid stars in Figure 2, respectively), which are the maximum values reached by $\mathrm{SCHL}(\mathrm{t})$ for $\mathrm{t}$ varying between 15 May and 15 November (summer) and for $t$ varying between 15 November and 15 May (winter). $t_{\max }^{\text {sum }}$ and $t_{\max }^{\text {win }}$ are defined as the time when SCHL(t) equals $S C H L_{\max }^{\text {sum }}$ and $S C H L_{\max }^{\text {win }}$, respectively. Thus, by definition, $t_{\max }^{\text {sum }}$ lies between 15 May and 15 November and $t_{\max }^{\text {win }}$ between 15 November and 15 May.

[19] In some instances, we could not find an SCHL maximum both during winter and during summer. These instances correspond to cases with a unique bloom along the seasonal cycle. The white areas in Figure $3 \mathrm{~b}$ show the locations where no winter bloom could be found (an example of this situation is that of station F, Figure 2). There are also a few locations in Figure $3 \mathrm{a}$ with no summer bloom. These white areas taken together mark the regions where only one bloom occurs along the seasonal cycle; in such cases, the algorithm searched for the time $t_{\min }$ of the SCHL absolute minimum, between 1 January and 31 December (open circle in mid-February in the case of station F, Figure 2).

[20] In the more general case of two blooms, the algorithm searched for $t_{\text {min }}^{\text {win }}$ (solid circles in Figure 2), the time of the minimum of SCHL between $t_{\max }^{\text {sum }}$ and $t_{\max }^{\text {win }}$, and for $t_{\mathrm{min}}^{\text {sum }}$ (open circles in Figure 2), the time of the minimum of SCHL between $t_{\max }^{\text {win }}$ and $t_{\max }^{\text {sum }}$. Note that the time of the bloom peak $t_{\max }$ was constrained within a prescribed 6month time interval, while the time of the bloom onset $t_{\text {min }}$ was only constrained to precede the corresponding $t_{\max }$. Thus the onset of summer blooms does not necessarily occur in summer, and often occurs before 15 May, and the onset of winter blooms also sometimes occur before 15 November (Figure 2).

[21] If more than one bloom occurs within a given season, then by definition this method treats it as a single bloom, which extends from the minimum of SCHL to the maximum of SCHL, regardless of oscillations in between these two extrema. This situation was found to be very rare because the SCHL climatology is rather smoothed.

[22] In each location, the seasonal cycle of SCHL was thus described by this ensemble of parameters: the winter and summer $t_{\min }, t_{\max }$ and CIC. In the following, we focus on the winter and summer $t_{\min }$ and CIC (Figure 3).

\subsection{Physical Parameters}

[23] The model parameters that we used are the mixedlayer depth (MLD), the horizontal currents $(U, V)$, and the vertical velocities $(W)$. We averaged $U$ and $V$ over the first $30 \mathrm{~m}$ because what is seen by the seacolor satellite is not strictly the surface, but represents an average over the mixed layer. Accordingly, we used $W$ at $30 \mathrm{~m}$ depth for our diagnostics.

[24] Figure 4 shows these model parameters for the winter and summer blooms. $U$ and $V$ are averaged over the bloom period. $W$ is cumulated in time rather then averaged, and therefore expressed in meters, in order to give an idea of the thickness of the upwelled volume of water. In the Indian Ocean, the MLD has a strong seasonality and its depth rarely exceeds $30 \mathrm{~m}$ during intermonsoon periods. Therefore for the MLD, we choose to show the maximum MLD reached during the bloom period, giving an indication of the MLD entrainment during the bloom and of the deepest layer connected with the surface through this entrainment. The maps in Figure 4 are not synoptic; they provide information for the bloom period, which varies regionally (Figure 3).

\subsection{Identification of the Mechanisms Driving the Blooms}

[25] The most general case is when nutrients are initially exhausted at the surface and the bloom is triggered by a dynamical supply of inorganic nutrients. This input of nutrients can be mediated by upwelling, by convection, or by horizontal advection. In such cases, examination of the physical fields over the bloom region provides a reasonable indication of the nutrient transport pathway. For example, a pattern of deep MLD during the bloom period can be thought of as the signature of a region of preferential nutrient entrainment during the phase of ML deepening. Note that this pattern is only indicative as it does not account for the exact MLD change; nor does it account for the vertical nutrient profile. Similarly, a pattern of upward (positive) vertical velocity during the bloom is indicative of the upwelling of nutrients at the surface, regardless of the mean gradients. $U$ and $V$ during the bloom period illustrate the potential for horizontal advection; the horizontal advection concerns not only the nutrients, but also dissolved organic material, which are longer lived

\footnotetext{
Figure 3. (a) Cumulated increase in chlorophyll $\left(\log _{10}(\mathrm{CIC})\right.$ ) for blooms peaking during the summer semester. (b) The $\log _{10}$ (CIC) for blooms peaking during the winter semester. (c) Time of the onset of summer blooms $\left(t_{\mathrm{min}}^{\text {sum }}\right)$. (d) Time of the onset of winter blooms $\left(t_{\mathrm{min}}^{\text {win }}\right)$. (e) Regionalization of summer blooms. (f) Regionalization of winter blooms. In Figures 3a and $3 \mathrm{~b}$, regions where no bloom is detected during the given semester are shown as missing data (white areas). In Figures $3 \mathrm{c}$ and $3 \mathrm{~d}$, areas of low CIC variability (purple areas in Figures $3 \mathrm{a}$ and $3 \mathrm{~b}$ ) have been masked. CIC are shown in log scale, and expressed in $\log 10\left(\mathrm{mgChl} / \mathrm{m}^{3} 8 \mathrm{~d}\right)$ ( 8 days is the frequency of the SeaWiFS climatology). Time is expressed in month, and each month is associated with one color. The month color bar is only applicable to Figures $3 \mathrm{c}$ and $3 \mathrm{~d}$, and has no bearing on Figures $3 \mathrm{e}$ and $3 \mathrm{f}$. Acronyms in Figures $3 \mathrm{e}$ and $3 \mathrm{f}$ are defined in the caption of Table 1.
} 
a) Summer CIC

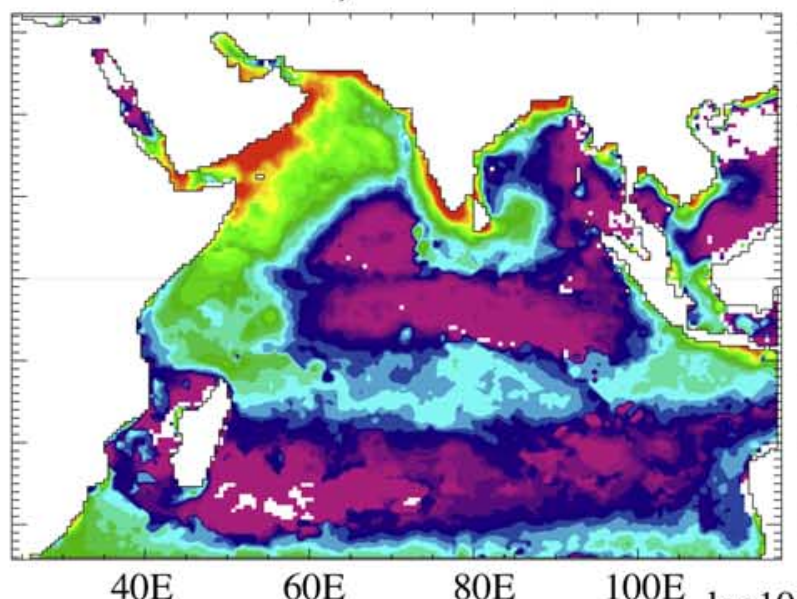

80E $100 \mathrm{E} \log 10(\mathrm{mg} \mathrm{Chl} / \mathrm{m} 38 \mathrm{~d})$

b) Winter CIC

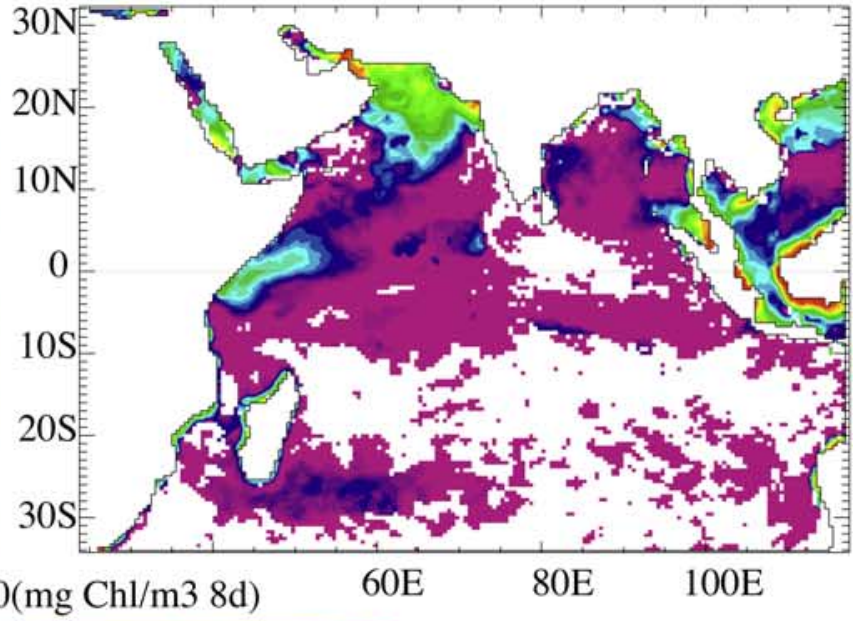

$\begin{array}{llllllllllll}-0.7 & -0.5 & -0.3 & -0.1 & 0.1 & 0.3 & 0.5 & 0.7 & 0.9 & 1.1 & 1.3 & 1.5\end{array}$

c) Month of summer bloom onset

d) Month of winter bloom onset
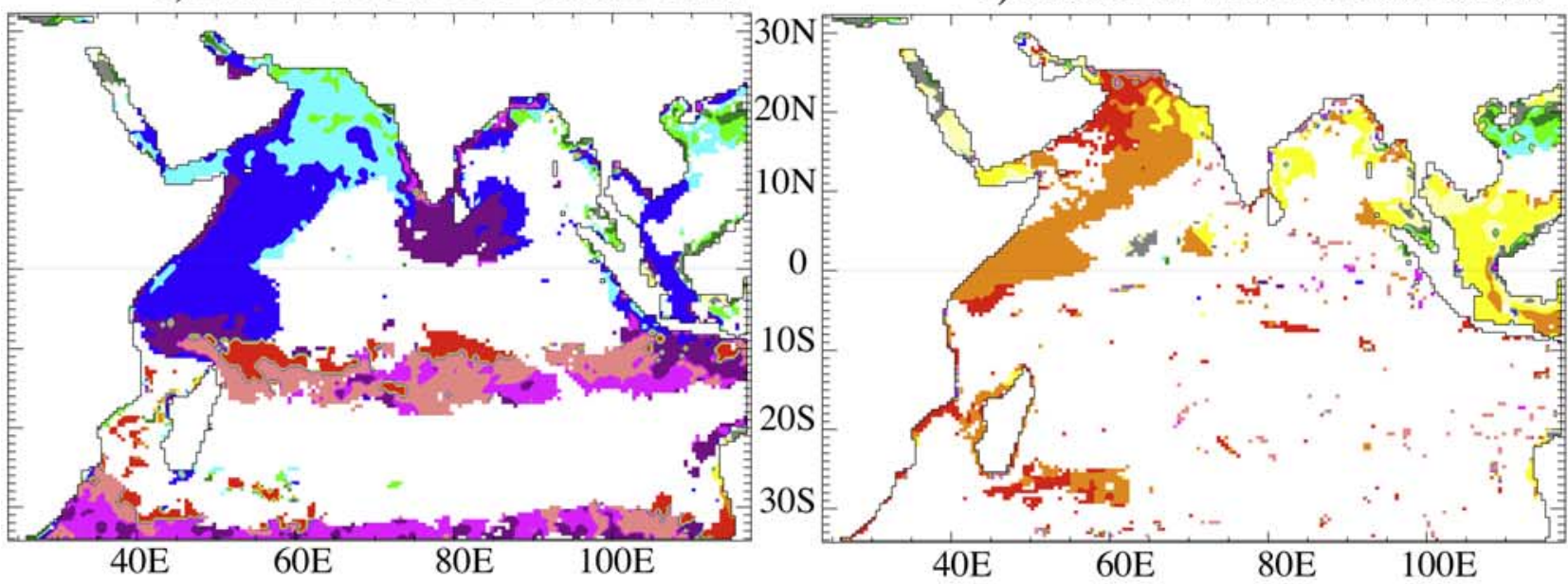

J F M A M J J A S O N D

e) Summer bloom regions

f) Winter bloom regions

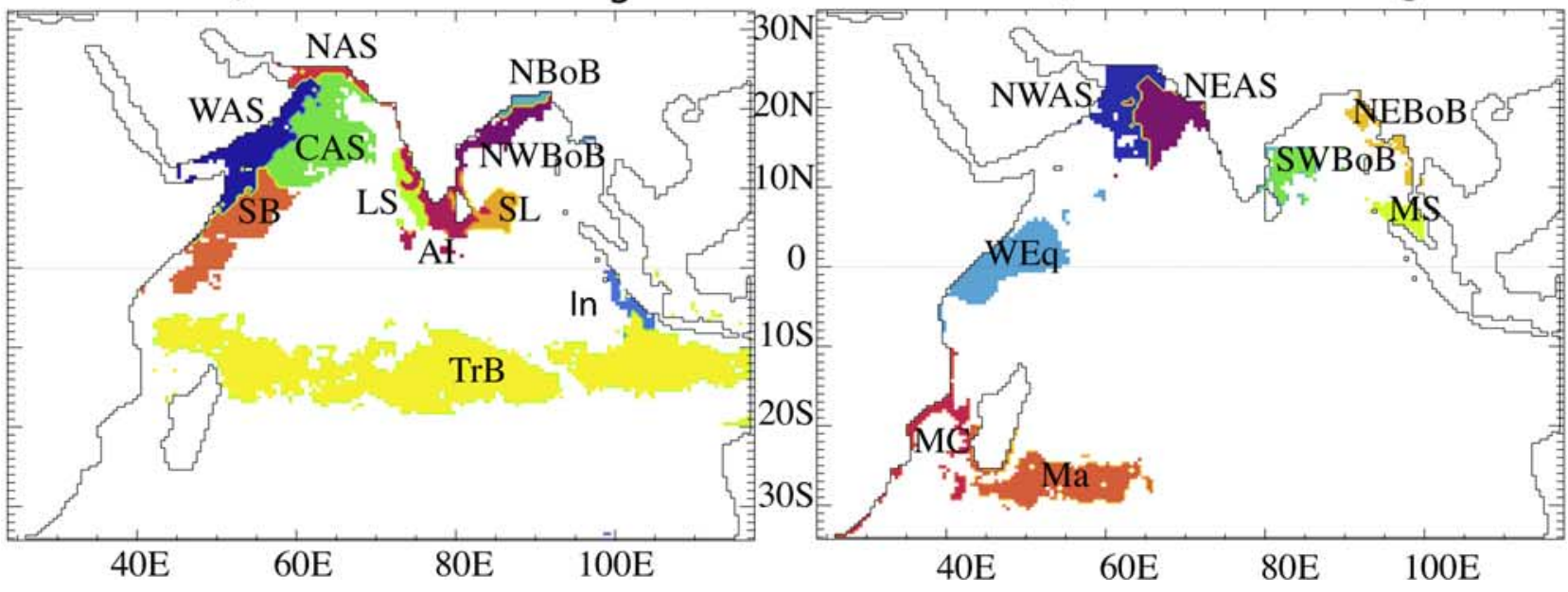

Figure 3 
a) U,V during summer blooms

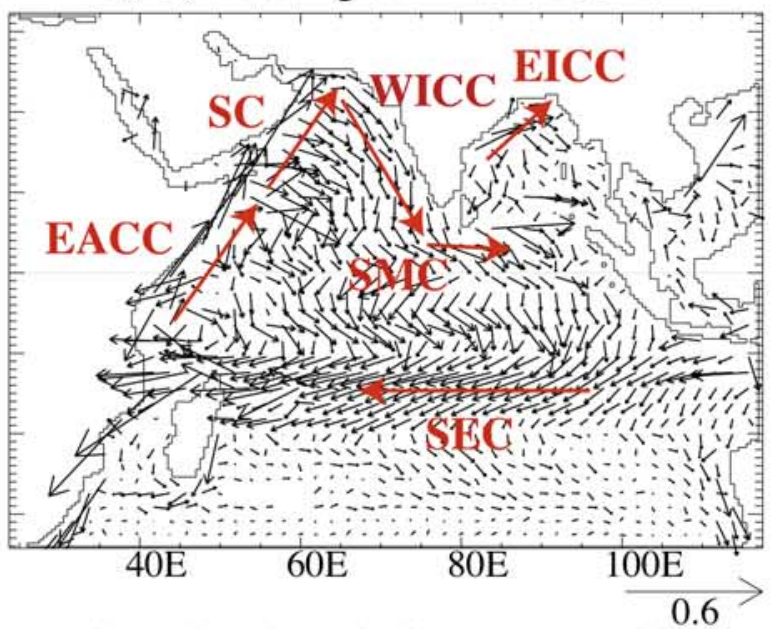

c) Cumulated $\mathrm{W}$ during summer blooms

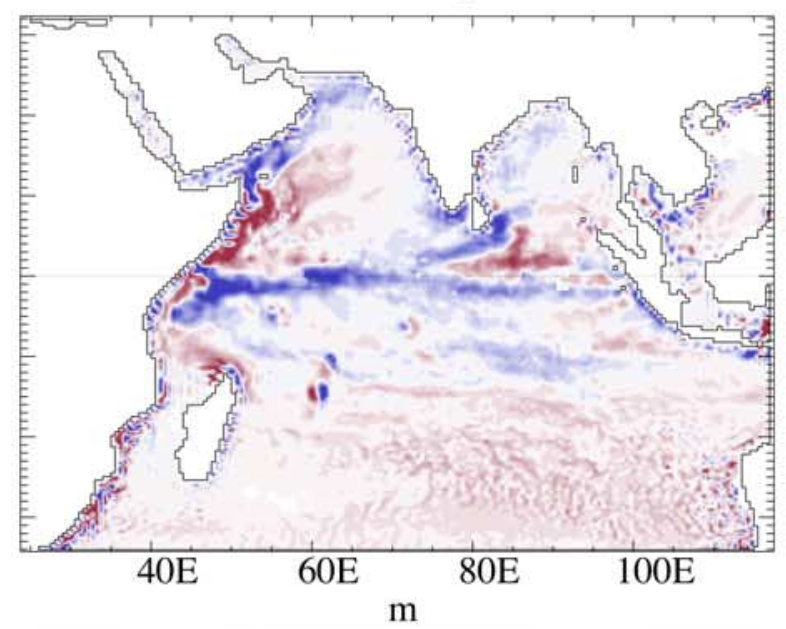

$-250-200-150-100 .-50.0 . \quad 50.100 .150 .200 .250$.

e) Max MLD during summer blooms

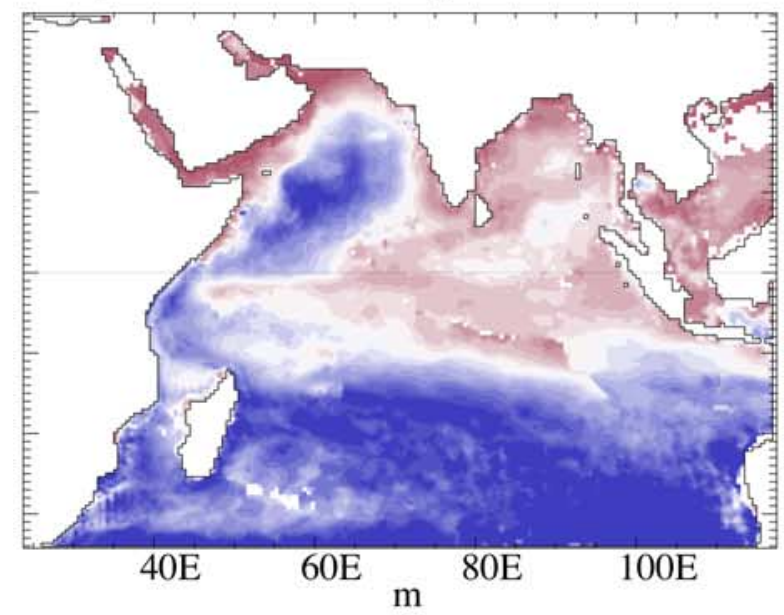

0. 10. 20. 30. 40. 50. 60. 70. 80. 90. 100. b) U,V during winter blooms

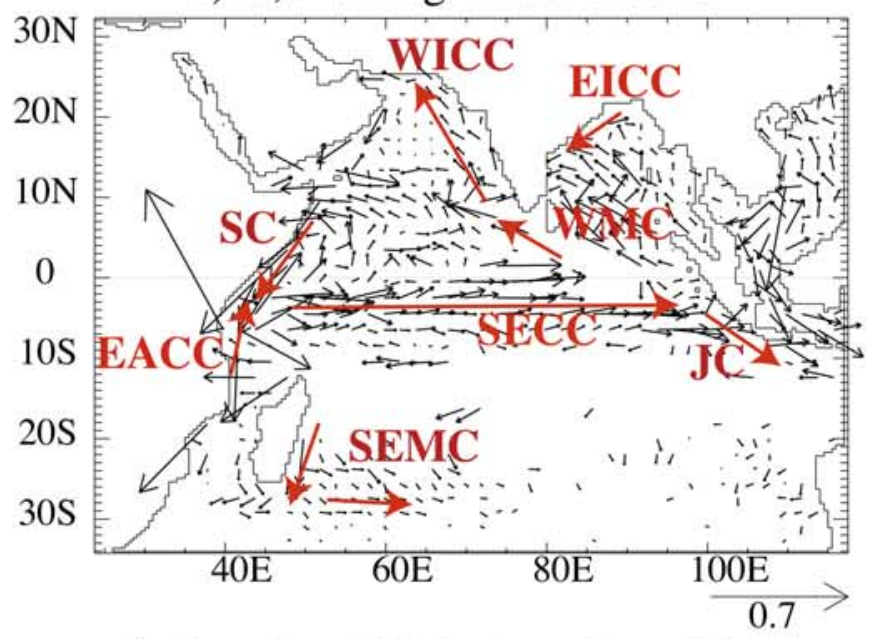

d) Cumulated $\mathrm{W}$ during winter blooms

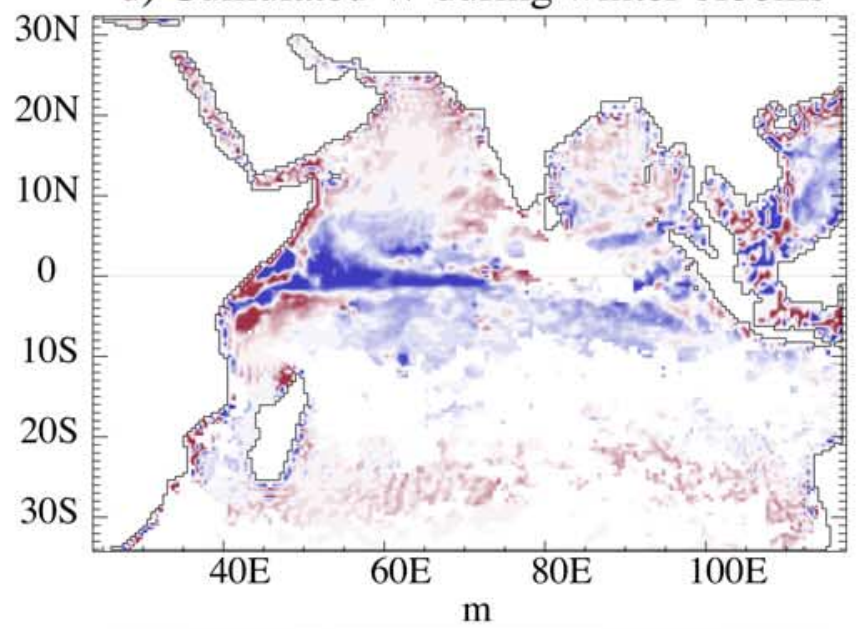

-100.-80. $-60 .-40 .-20.0 . \quad 20.40 .60 .80 .100$.

f) Max MLD during winter blooms

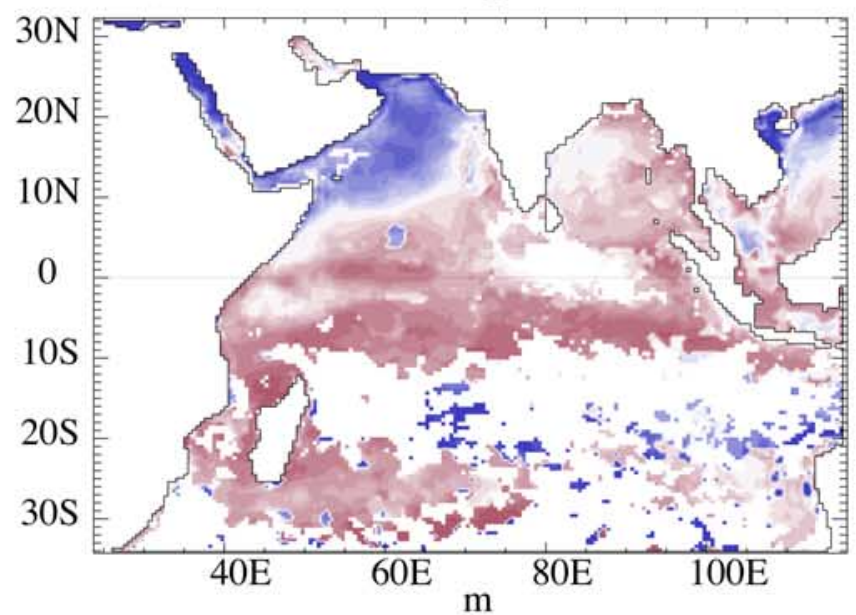

0. 10.20 .30 .40 .50 .60 .70 .80 .90 .100$.

Figure 4 
than nutrients and have the potential to be transported over long distances and remineralized into inorganic nutrients progressively.

[26] Nevertheless, examination of the physical fields alone cannot distinguish between regions where the bloom is nutrient-limited and regions where it is not (or is less nutrient-limited). When available, we will use additional published information to corroborate the mechanisms that are suggested by our simple comparison. In particular, one limitation of the method concerns the interpretation of the MLD pattern. It is convenient to use the example of the North Atlantic to illustrate this issue [Lévy et al., 2005]. In the subtropical north Atlantic, phytoplankton production is nutrient-limited and the bloom occurs in winter, when the mixed layer deepens enough to erode the nutricline; in this case, the bloom is triggered by the convective supply of nutrients. At higher latitudes, the mixed-layer deepening severely limits photosynthesis because the mean irradiance experienced by the cells is too low; the bloom can only occur in spring, when the mixed-layer stratifies. It is presumable (and it has previously been suggested [Marra and Barber, 2005]) that at the latitude of the Indian Ocean, irradiance never seriously limits photosynthesis and that a deep mixed layer is indicative of nutrient supply rather than irradiance limitation. Moreover, Marra and Barber [2005] have also suggested that in the Arabian Sea, the main effect of the deepening of the mixed layer is to dilute zooplankton along with phytoplankton; this dilution allows phytoplankton to escape grazing losses and to start growing. Again, it is not possible to identify this dilution mechanism with the present method; what can be done, however, is to state, regionally, whenever a bloom occurrence is associated with a pattern of deep MLD.

\section{Seasonal Cycles of Phytoplankton}

[27] In this section, we describe the phytoplankton blooms in the Indian Ocean on the basis of Figures $3 a-3 d$. This description then guides the regionalization of summer and winter blooms (Figures 3e and 3f). Finally, we reconstruct average seasonal cycles over the regions that have been defined (Figure 5).

\subsection{Intensity and Timing of the Blooms in the Indian Ocean}

[28] North of $10^{\circ} \mathrm{S}$, the SCHL seasonal cycle was characterized by two peaks almost everywhere (Figures 3a, 3b, and 5). The exceptions were the regions around the southern tip of India and around Sri Lanka, where there was only a summer peak (white areas in Figure $3 \mathrm{~b}$ ). South of $10^{\circ} \mathrm{S}$, most of the tropical ocean was characterized by a single peak, which occurred in summer (i.e., during austral winter, Figure 3). A second peak appeared in winter to the east of Madagascar as well as in the Mozambique channel (see also Figure 5).

[29] There were large regional contrasts in the intensity of the summer and winter blooms. During summer (Figure 3a), the main bloom areas were along the coasts of the Arabian Sea, in the open Arabian Sea, around Sri Lanka up to the southwestern Bay of Bengal, in the northwest Bay of Bengal, along the coast of Indonesia, and in a subtropical band centered on $13.5^{\circ} \mathrm{S}$. During winter (Figure $3 \mathrm{~b}$ ), the main blooms were in the northern Arabian Sea, in the western equatorial region, in the western Bay of Bengal, in the northeast Bay of Bengal, around the Malacca strait, to the east of Madagascar, and in the Mozambique channel. The purple areas in Figures $3 \mathrm{a}$ and $3 \mathrm{~b}$ are regions where the amplitude of the seasonal variations was very small. They are not considered in the following description and analysis.

[30] Figures $3 \mathrm{c}$ and $3 \mathrm{~d}$ show the timing of the bloom onsets $\left(t_{\mathrm{min}}^{\text {win }}\right.$ and $\left.t_{\mathrm{min}}^{\text {sum }}\right)$. A striking result is that they showed distinct regional patterns. Summer blooms started in March off the coasts of Somalia, Oman, and India, and in the region around Sri Lanka (Figure 3c). In the open Arabian Sea, the blooms started in April between $10^{\circ} \mathrm{S}$ and $10^{\circ} \mathrm{N}$, in May north of $10^{\circ} \mathrm{N}$, and as late as June along the Pakistani coast and in the Gulf of Oman. In the $10^{\circ} \mathrm{S}$ subtropical band, the bloom started between December and January. Note also the clear separation of that band from the region just north of $10^{\circ} \mathrm{S}$ in terms of bloom timing. Winter blooms started in October in the northeastern Arabian Sea, in the Gulf of Aden, and in the Bay of Bengal (Figure 3d). They started one month later in the central Arabian Sea and the equatorial region, and as late as December in the northwestern Arabian Sea and east of Madagascar.

\subsection{Regionalization of the Blooms in the Indian Ocean}

[31] In Figures $3 e$ and $3 f$, we propose a regionalization of the summer and winter blooms. The principle that we follow is to delimit regions with fairly homogeneous values of $\log _{10}$ (CIC) and $t_{\text {min }}$. The values of the $\log _{10}$ (CIC) contours (Table 1) were chosen to highlight the regions that naturally emerge from visual inspection of Figures $3 \mathrm{a}$ and 3b. Note that different contour intervals were needed for different regions, reflecting the regional variations of the amplitude of CIC. When large variations of $t_{\text {min }}$ occurred over the regions defined with the CIC contours, we used $t_{\text {min }}$ contours to define smaller subregions (Table 1). This was, for example, the case of the winter North West Arabian Sea (NWAS) and North East Arabian Sea (NEAS) regions: they corresponded to fairly similar $\log _{10}$ (CIC) values (Figure $3 b$ ), but were separated by a strong $t_{\min }$ gradient (Figure $3 \mathrm{~d}$ ).

Figure 4. Mean horizontal currents averaged over $0-30 \mathrm{~m}(\mathrm{U}-\mathrm{V})$, time-cumulated vertical velocity (at $30 \mathrm{~m})$ and maximum mixed-layer depth (MLD) during the summer and winter blooms in the model climatology. Note that the maps are not synoptic; they provide information for the bloom period, which varies regionally (Figure 3). Some of the main currents have been identified on the basis of the description by Schott and McCreary [2001, Figures 8 and 9] and Shankar et al. [2002]: the South Equatorial Current (SEC), the East African Coast Current (EACC), the Somali Current (SC), the West India Coastal Current (WICC), the Summer Monsoon Current (SMC), the East India Coastal Current (EICC), the South Equatorial Counter Current (SECC), the South Java Current (JC), the Winter Monsoon Current (WMC), and the South East Madagascar Current (SEMC). Note that the SMC and WMC are transbasin currents and flow between the Arabian Sea and the Bay of Bengal during their mature phase [Shankar et al., 2002]. 
[32] In the case of the summer blooms (Figure 3e), four regions were characterized by very high CIC (red areas in Figure 3a): the coastal band off Pakistan in the North of the Arabian Sea (NAS), the West Arabian Sea (WAS), the region around India (AI), and a small region in the Northern Bay of Bengal (NBoB). Of lower CIC intensity were the regions of the Central Arabian Sea (CAS), Somali Basin (SB), Lak-

a) WAS (plain) and NAS (dashed) b) CAS (plain) and SB (dashed)

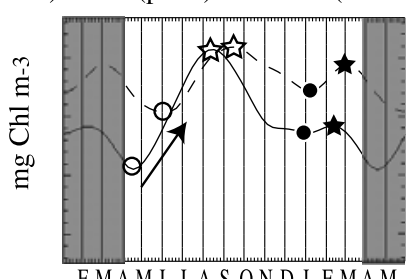

FMAM J J A S OND J F MAM c) $\mathrm{NBoB}$ (plain) and NWBoB (dashed)

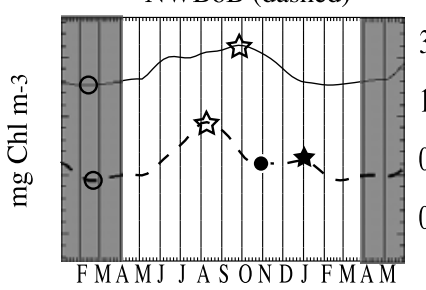

e) In

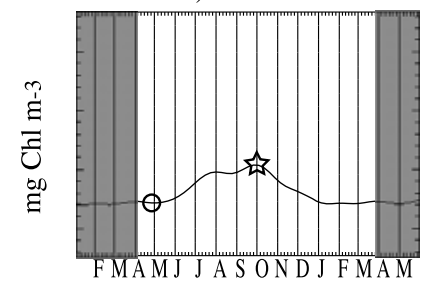

g)NWAS (plain) and NEAS (dashed)

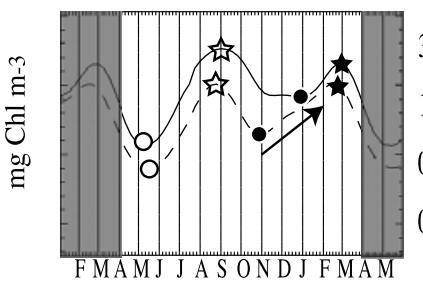

i) $\mathrm{MS}$

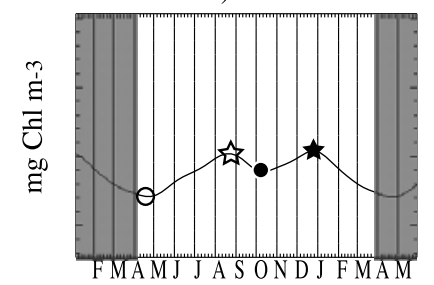

k) NEBoB

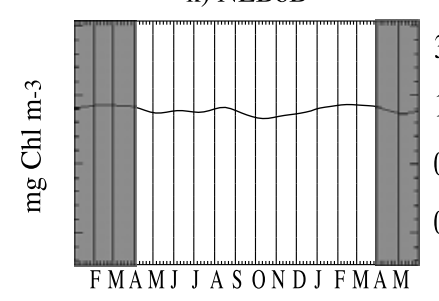

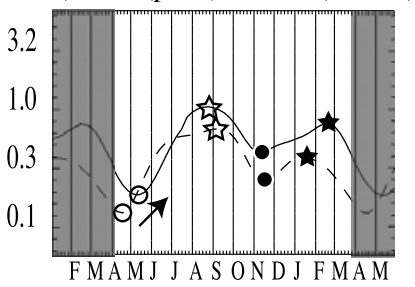

d) AI (plain), LS (dashed), SL (dotted)

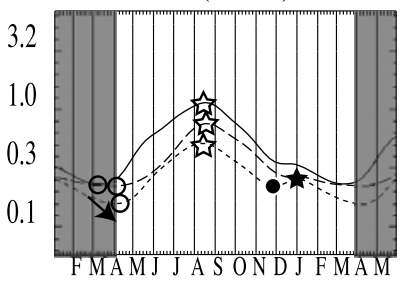

f) $\mathrm{TrB}$

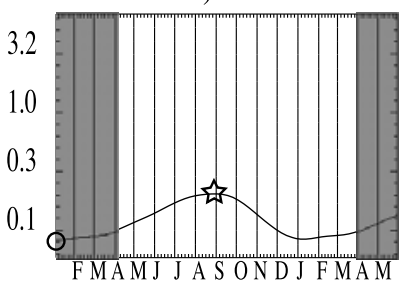

h) Weq

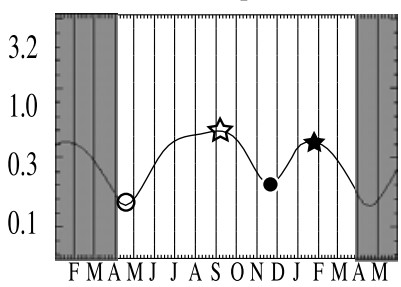

j) $\mathrm{SWBoB}$

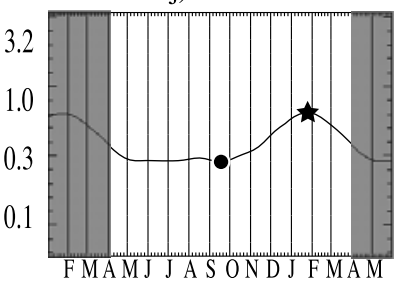

1)Ma (plain) and MC (dashed)

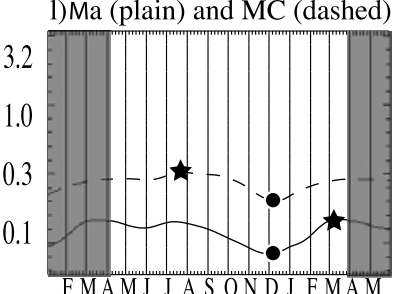

shadweep Sea (LS), the tongue-shaped region to the east of Sri Lanka (SL), the North West Bay of Bengal (NWBoB), a region along the coast of Indonesia (In), and a Tropical Band (TrB) located between $10^{\circ} \mathrm{S}$ and $17^{\circ} \mathrm{S}$.

[33] In the case of the winter blooms, this method led to the detection of the following regions: North West Arabian Sea (NWAS) and North East Arabian Sea (NEAS), the South West Bay of Bengal (SWBoB), a coastal area in the North East Bay of Bengal (NEBoB), the Malacca Strait region (MS), the West Equatorial (Weq), the Madagascar region (Ma), and the Mozambique Channel region (MC) (Figure 3f).

[34] As we shall see, this empirical method led to a reasonable identification of biophysical provinces. The regions of the summer and winter blooms were quite different, emphasizing again the large variations in physical forcing associated with the monsoons. There was, however, some overlapping between the summer and winter provinces, particularly in the Arabian Sea.

\subsection{Regional Description of the Seasonal Cycles}

[35] Figures $5 \mathrm{a}-5 \mathrm{f}$ show the seasonal cycles of SCHL averaged over the summer bloom regions defined in Figure 3 e. Similarly, Figures $5 \mathrm{~g}-51$ show the seasonal cycles over the winter bloom regions defined in Figure 3f. This reconstruction enabled us to describe the complete seasonal cycle. As mentioned before, some of the summer regions in Figure $3 \mathrm{e}$ overlapped the winter regions in Figure $3 \mathrm{f}$. This was the case for the West equatorial region (Figure 3f) and Somali Basin region (Figure 3e), which exhibited similar seasonal cycles (Figures $5 \mathrm{~b}$ and $5 \mathrm{~h}$ ). This was also the case for the North East Arabian Sea region (Figure 3f) and the Central Arabian Sea regions (Figure 3e) (Figures $5 \mathrm{~b}$ and $5 \mathrm{~g}$ ).

[36] The regions characterized by two peaks of comparable amplitude (solid and open stars in Figure 5) were essentially located in the Arabian Sea west of $70^{\circ}$ E. These regions are the North Arabian Sea (Figure 5a), Central Arabian Sea (Figure 5b), Somali Basin (Figure 5b), North West Arabian Sea (Figure 5g), North East Arabian Sea (Figure $5 \mathrm{~g}$ ), and West equatorial Indian Ocean (Figure 5h).

[37] In contrast, within the regions around India, in the Lakshadweep Sea, and around Sri Lanka, the seasonal signal was completely dominated by the summer bloom (Figure 5d). There was no winter bloom, in the sense that there was no significant increase of SCHL during winter, although SCHL concentrations in winter were not necessarily weak. The summer bloom also lasted longer than in the other regions of the Arabian Sea and what was actually

Figure 5. Seasonal cycles of SCHL averaged over the regions defined in Figures 3e and 3f. Acronyms are defined in the caption of Table 1. $(\mathrm{a}-\mathrm{f})$ Summer bloom regions and $(\mathrm{g}-\mathrm{l})$ winter bloom regions. Bloom onsets are marked with circles and bloom peaks are marked with stars. Open symbols are used for summer blooms, and solid symbols are used for winter blooms. Arrows in Figures 5a, 5b, 5d, and $5 \mathrm{~g}$ identify the main time shifts in the onset of blooms discussed in the text. Note that for clarity, the months January to May are repeated at the beginning and at the end of the plots; the repeated part of the seasonal cycle is shaded. The ordinate is in $\log$ scale. Units are $\mathrm{mg} \mathrm{Chl} / \mathrm{m}^{3}$. 
Table 1. Range of $\log _{10}$ (CIC) and of $t_{\min }$ Used to Define Each Summer and Winter Bloom Region ${ }^{\mathrm{a}}$

\begin{tabular}{cccc}
\hline Period & Region & $\log 10(C I C)$ & $t_{\text {min }}$ \\
\hline Summer & NAS & $1<\log 10(C I C)$ & $t_{\min }>15$ May \\
& WAS & $1<\log 10(C I C)$ & $t_{\min }<15$ May \\
& CAS & $0.5<\log 10(C I C)$ & $t_{\min }>20$ April \\
& SB & $0.5<\log 10(C I C)$ & $t_{\min }<20$ April \\
& AI & $1<\log 10(C I C)$ & $t_{\min }<15$ March \\
& LS & $0.25<\log 10(C I C)<1$ & $t_{\min }>15$ March \\
& SL & $0.25<\log 10(C I C)<1$ & - \\
NWBoB & $0<\log 10(C I C)<1$ & - \\
NBoB & $1<\log 10(C I C)$ & 1 April $<t_{\text {min }}$ \\
& In & $0<\log 10(C I C)<0.5$ & $t_{\min }>1$ October or \\
& TrB & $0<\log 10(C I C)<0.5$ & $t_{\min }<1$ April \\
& NWAS & $0<\log 10(C I C)$ & $t_{\min }>15$ November \\
& NEAS & $0<\log 10(C I C)$ & $t_{\min }<15$ November \\
& SWBoB & $-0.5<\log 10(C I C)$ & - \\
& NEBoB & $0<\log 10(C I C)$ & - \\
& MS & $-0.1<\log 10(C I C)$ & - \\
& Weq & $-0.2<\log 10(C I C)$ & - \\
& Ma & $-0.5<\log 10(C I C)$ & - \\
MC & $-0.5<\log 10(C I C)$ &
\end{tabular}

${ }^{\mathrm{a}}$ The $\log _{10}$ (CIC) values refer to Figures $3 \mathrm{a}$ and $3 \mathrm{~b} ; t_{\min }$ values refer to Figures $3 \mathrm{c}$ and $3 \mathrm{~d}$. When $t_{\min }$ is left vacant, no condition on $t_{\min }$ was needed to distinguish between adjacent regions. Abbreviations: NAS, North Arabian Sea; WAS, West Arabian Sea; AI, around India; NBoB, North Bay of Bengal; CAS, Central Arabian Sea; SB, Somali Basin; AI, Around India.; LS, Lakshadweep Sea; SL, Sri Lanka region; NWBoB, North West Bay of Bengal; NBoB, North Bay of Bengal; In, Indonesia; TrB, Tropical Band; NWAS, North West Arabian Sea; NEAS, North East Arabian Sea; SWBoB, South West Bay of Bengal; NEBoB, North East Bay of Bengal; MS, Malacca Strait region; Weq, West Equatorial.; Ma, Madagascar; MC, Mozambique Channel.

observed in winter, during the period of the strongest winter monsoon winds (December-January), is the continuation of the decay of the summer bloom.

[38] In the Bay of Bengal, the winter and summer bloom regions were quite distinct. Consequently, over most of the Bay of Bengal, the seasonal cycles of SCHL were characterized by a single significant peak, either during summer or during winter, depending on the location (Figures 5c, 5d, and $5 \mathrm{j}$ ). One exception was the Malacca Strait region (Figure 5i), where SCHL peaked in late August and in late December. The North East Bay of Bengal (Figure 5k) was rather inhomogeneous in terms of seasonal cycles (see, for instance, the great amount of variability in $t_{\min }$ in Figure $3 \mathrm{~d}$ ). Consequently, it revealed no apparent mean seasonal variations because of compensations from one location to the other (not shown).

[39] In the Southern Hemisphere, the Tropical Band was characterized by a slow increase of SCHL from January to the end of August (Figure 5f). Off the coast of Indonesia, there was also one significant bloom, which started increasing in June (Figure 5e). In the Madagascar and Mozambique Channel regions, there was a small increase of SCHL from December to March, followed by a slow decrease during the rest of the year, with some weak fluctuations (Figure 51).

[40] Besides, the reconstruction of the seasonal cycles enabled the identification of significant lags in the onset of blooms in spatially adjacent regions (the onset times are identified by circles in Figure 5). For summer blooms (open symbols in Figure 5), the main lags were found between the West and North Arabian Sea (indicated by an arrow in Figure 5a), between the Central Arabian Sea and the Somali
Basin (arrow in Figure 5b), and between the regions around India, the Lakshadweep Sea, and around Sri Lanka (arrow in Figure 5d). For winter blooms (solid symbols in Figure 5), there was a significant lag between the North East and the North West Arabian Sea (arrow in Figure 5g).

\section{Physical Interpretation of the Blooms}

[41] Finally, we relate the blooms to the near-surface physical environment in the model climatology by examining the physical patterns (Figure 4) over the bloom regions (Figures $3 \mathrm{e}$ and $3 \mathrm{f}$ ). As we shall see, the bloom regions that have been previously distinguished on the basis of the SCHL climatology correspond to well-identified physical characteristics. These bloom regions are now described in more details and summarized in Table 2.

\subsection{Physical Driving Mechanisms of Summer Blooms}

[42] In summer, the most obvious event is the prominent phytoplankton bloom extending oceanward from the coasts of the Arabian peninsula into the open Arabian Sea (Figure 3a) [Brock et al., 1991; Banzon et al., 2004; Wiggert et al., 2005]. It is well established that upwelling is responsible for this bloom (see Wiggert et al. [2005] for a review). The upwelling ensues from the strong southwesterly monsoon wind that runs diagonally across the Arabian Sea [Findlater, 1969; Schott and McCreary, 2001]. Lateral variations in wind stress to either side of the wind jet drive Ekman pumping [see Lee et al., 2000, Figures 1 and 16], forcing open ocean upwelling to the north of the wind-stress maximum (in the western Arabian Sea) and downwelling to the south (in the central Arabian Sea) (Figure 4c). Moreover, the alongshore component of the wind jet drives coastal upwelling along the Arabian coast, which combines with the positive contribution of Ekman pumping. There was a striking correspondence between the shape of the areas of high summer CIC (West Arabian Sea, North

Table 2. Main Dynamical Signatures Over the Bloom Regions ${ }^{a}$

\begin{tabular}{|c|c|c|c|}
\hline Region & W & MLD & U,V \\
\hline \multicolumn{4}{|c|}{ Summer Period } \\
\hline NAS & $\mathrm{Y}$ & $\mathrm{N}$ & $\mathrm{Y}$ \\
\hline WAS & $\mathrm{Y}$ & $\mathrm{N}$ & $\mathrm{N}$ \\
\hline CAS & $\mathrm{N}$ & $\mathrm{Y}$ & $\mathrm{Y}$ \\
\hline SB & $\mathrm{N}$ & $\mathrm{Y}$ & $\mathrm{Y}$ \\
\hline AI & $\mathrm{Y}$ & $\mathrm{N}$ & $\mathrm{N}$ \\
\hline LS & $\mathrm{Y}$ & $\mathrm{N}$ & $\mathrm{N}$ \\
\hline SL & $\mathrm{Y}$ & $\mathrm{N}$ & $\mathrm{Y}$ \\
\hline NWBoB & $\mathrm{Y}$ & $\mathrm{N}$ & $\mathrm{N}$ \\
\hline $\mathrm{NBoB}$ & $\mathrm{N}$ & $\mathrm{N}$ & $\mathrm{N}$ \\
\hline In & $\mathrm{Y}$ & $\mathrm{N}$ & $\mathrm{N}$ \\
\hline $\operatorname{TrB}$ & $\mathrm{Y}$ & $\mathrm{Y}$ & $\mathrm{N}$ \\
\hline \multicolumn{4}{|c|}{ Winter Period } \\
\hline NWAS & $\mathrm{N}$ & $\mathrm{Y}$ & $\mathrm{N}$ \\
\hline NEAS & $\mathrm{N}$ & $\mathrm{Y}$ & $\mathrm{Y}$ \\
\hline SWBoB & $\mathrm{Y}$ & $\mathrm{Y}$ & $\mathrm{N}$ \\
\hline NEBoB & $\mathrm{N}$ & $\mathrm{N}$ & $\mathrm{N}$ \\
\hline MS & $\mathrm{Y}$ & $\mathrm{N}$ & $\mathrm{N}$ \\
\hline Weq & $\mathrm{Y}$ & $\mathrm{N}$ & $\mathrm{N}$ \\
\hline $\mathrm{Ma}$ & $\mathrm{Y}$ & $\mathrm{N}$ & $\mathrm{Y}$ \\
\hline $\mathrm{MC}$ & $\mathrm{Y}$ & $\mathrm{N}$ & $\mathrm{N}$ \\
\hline
\end{tabular}

a Abbreviations: $W$, upwelling; MLD, deep mixed-layer; $U$ and $V$, strong horizontal currents); Y, yes; and N, no. Acronyms are defined in the caption of Table 1 . 
Arabian sea, and Around India regions; Figures 3a and 3e) and the patterns of vertical velocity in summer (Figure 4c). See, in particular, the larger offshore extension of upwelling along Oman and Yemen compared to Somalia, in correspondence with the narrowing of the West Arabian Sea region off Somalia. This correspondence clearly indicates that upwelling of nutrients is the principal driving factor.

[43] Farther offshore, the bloom was found away from the direct influence of upwelling, and was colocated with the pattern of deep mixed layers (Figure 4c). The model actually revealed a marked bowl shape of deep MLDs in the Central Arabian Sea (Figure 4e), with deeper MLDs overlying the region of downward Ekman pumping and shallower MLDs the areas of upward vertical velocity (Figure 4c). This MLD pattern is in agreement with the MLD climatology of de Boyer Montégut et al. [2004] and with the Arabian Sea JGOFS mooring data [Weller et al., 2002]. Mixed-layer deepening results from the strong summer monsoon winds that drive mixing through both mechanical stirring and convective overturning; it is facilitated in areas of downward Ekman pumping, where surface stratification is weaker than in regions of upwelling. The Central Arabian Sea is also a region fed by waters originating from the western boundary by horizontal advection: it was characterized by strong offshore horizontal currents during the bloom period (Figure 4a).

[44] From these simple observations of the physical features, there are a number of processes that can be advocated to explain the bloom in the Central Arabian Sea. If we assume that the bloom is nutrient-limited, then the first plausible hypothesis is that the deepening of the mixed layer during the summer monsoon is associated with an entrainment of nutrients. The second hypothesis is that the Central Arabian Sea is fed by horizontal advection of nutrients originating from the coast; the transport can either concern inorganic nutrients brought up in excess (i.e., upwelling is too dispersive to allow blooms to fully form near shore prior to upwelled waters being laterally advected away [Hitchcock et al., 2000]), or dissolved organic material, produced in the upwelling region and progressively remineralized along their offshore journey. The model results of Young and Kindle [1994] and of Kawamiya [2001] suggest that the Central Arabian Sea bloom results from horizontal advection from the coastal areas, with a smaller contribution from vertical mixing. Mooring data also suggest that advection is essential in the thermal budget of the mixed-layer [Fischer et al., 2002]. In our analysis, the predominance of horizontal advection in driving the bloom is suggested by the cross-shore CIC gradient (Figure 3a) and is also consistent with the bloom beginning in the Central Arabian Sea approximately one month after the coastal Western Arabian Sea (Figure $3 c$ and Figures $5 a$ and $5 b$ ). A simple scaling shows that the advection hypothesis is consistent: the horizontal velocities in the surface layer are of the order of $0.1-0.2 \mathrm{~m} \mathrm{~s}^{-1}$, which permits feeding of the Central Arabian Sea region in 15-20 days.

[45] Note that minima in photosynthetic available radiation were reported during the summer monsoon (both from bio-optical moored time series [Dickey et al., 1998, Figure 3] and from satellites [Arnone et al., 1998]). These minima are due to this season's extreme cloudiness, which is more pervasive near shore. Thus intermittent light limitation near to the surface during the summer monsoon may also promote offshore transport of coastally upwelled nutrient and could partially explain the time delay (15-20 days) for dissolved inorganic nutrients to reach the Central Arabian Sea region and fuel the blooms observed there.

[46] Kumar et al. [2001] suggest distinguishing between the northern part of the Central Arabian Sea, north of the axis of the Findlater Jet, where Ekman pumping is upward and entrainment is stronger, and the southern part of the Central Arabian Sea, where advection from the Somali region dominates. The analysis presented here is consistent with the conclusions of Kumar et al. [2001]; see, in particular, Figures $4 \mathrm{c}$ and $4 \mathrm{e}$, which show shallower MLDs and upward vertical velocities in the northern part of the Central Arabian Sea region. The CIC and $t_{\min }$ distributions, however, do not support the division of the region into two smaller subregions: they were fairly homogeneous, with no significant north-south contrast. This homogeneity may be the result of horizontal advection dominating in both subregions, or indicative that another process prevails.

[47] This is actually what is proposed by Marra and Barber [2005]. They highlight that phytoplankton physiological rates and productivity measurements in the Central Arabian Sea suggest that phytoplankton are not strongly limited by either irradiance or nutrient supply. Their hypothesis is that vertical mixing affects grazing by diluting micrograzers, thus reducing the grazing pressure on phytoplankton and allowing the bloom to develop. This mechanism is consistent with our result that the Central Arabian Sea bloom is concomitant with the area of deep mixed layers. Moreover, that Marra and Barber [2005] find that nutrients are never limiting is certainly because horizontal advection and, to a lesser extent, convection act as continuous suppliers. In brief, the Central Arabian Sea appears as a complex region, with nutrients inputs by horizontal advection, by convection in its southern part and by upwelling in its northern boundary, and where the role of the limiting factors of photosynthesis and of vertical mixing remain to be further investigated.

[48] Note also that the eastward extension of the Central Arabian Sea bloom had a marked wedge shape. This wedge shape occurred because the Summer Monsoon Current is stronger in the Central Arabian Sea than farther north or south [Shankar et al., 2002]. Moreover, the Central Arabian Sea bloom was clearly separated from the bloom along the west coast of India by the West India Coastal Current (WICC) [Shankar and Shetye, 1997].

[49] The region of the Somali Basin had characteristics similar to that of the Central Arabian Sea region. It was colocated with downwelling and deep mixed layers, and was affected by offshore horizontal advection. The Somali Basin is the region of the seasonal gyre known as the Great Whirl (located around $8^{\circ} \mathrm{N}, 53^{\circ} \mathrm{W}$ ) and of the Southern Gyre (centered on the equator) [Schott and McCreary, 2001]. The large-scale spatial averaging is this study did not allow us to examine these structures in details, although there was some sign that upwelling could be at play in the Southern Gyre (Figure 4c). Although upwelling starts a month earlier off Oman than off Somalia, the strong upwelling burst begins first off Somalia, then off Oman [see Shankar, 1998, Figure 2.7]. This could explain the 
earlier bloom onset in the Somali Basin with respect to the Central Arabian Sea (Figure 3c and arrow in Figure 5b).

[50] The bloom in the North Arabian Sea, along the coast off Pakistan, was the last to start (arrow in Figure 5a). One factor associated with the timing of this bloom could be the late onset of the summer monsoon in the northern Arabian Sea. Another factor, which emerged during the US JGOFS (Joint Global Ocean Flux Study) program in the Arabian Sea, could be the strong offshore advection associated with the Ras al Hadd Jet, which carries into the North Arabian Sea the upwelled waters from the Oman coast [Manghnani et al., 1998; Kim et al., 2001]. The available data, from both direct current measurements and geostrophic estimates from altimetry, suggest strong intraseasonal [Flagg and Kim, 1998; Kim et al., 2001] and interannual [Manghnani et $a l ., 1998]$ variability in the flow field in this region, making it difficult to arrive at a climatological mean timing for the offshore advection from the Arabian shelf. The jet, however, has been associated earlier with the offshore advection of biogenic material from the upwelling regime on the Arabian coast [Kim et al., 2001].

[51] Around India, examination of the physical fields indicated that the bloom was driven by upwelling (Figure 4c). This was first suggested by Shetye et al. [1990] and McCreary et al. [1996]. In this region, the upwelling is forced both by remote winds from the east coast of India, through the generation of Rossby waves, and by local winds, but the first of these two forcings is stronger [Shankar and Shetye, 1997; Shankar et al., 2002].

[52] The offshore extension of the bloom around India was restricted to the marginal Lakshadweep Sea region, by the presence along the coast of the southward flowing WICC (Figure 4a). Figure 4c shows that the pattern of upwelling in the model extends off the shelf into the Lakshadweep Sea. This suggests that the Lakshadweep Sea bloom is forced locally by upwelling. Upwelling in the Lakshadweep Sea is forced remotely by Rossby waves generated at the coast and propagating westward [Shankar et al., 2004]. This view is consistent with the large time lag in the onset of the blooms between the region Around India and the Lakshadweep Sea (almost 2 months, Figure 5d) and the propagation speed of the waves [Shankar et al., 2004]; upwelling occurs later in the Lakshadweep Sea than at the coast, and this delay corresponds to the time needed by the waves to propagate. Unfortunately, the resolution of the model does not enable to illustrate this propagation.

[53] Lierheimer and Banse [2002] suggest, from visual inspection of Coastal Zone Color Scanner images, that the bloom in the Lakshadweep Sea results from occasional, zonal outbreaks of phytoplankton rich waters originating from the shelf in the form of filaments extending across half of the Lakshadweep Sea. It is not possible to detect such outbreaks in our smoothed climatology, but the outbreaks do not rule out the predominance of local upwelling.

[54] Advection along the Indian coast by the WICC and then around Sri Lanka by the Summer Monsoon Current (Figure $4 \mathrm{a}$ ) was presumably the main origin of the bloom around Sri Lanka and of its tongue shape. Again, this view is confirmed by the time lag between the onset of the blooms Around India and Sri Lanka (Figure 5d). There is also evidence for local upwelling in the Sri Lanka region (Figure 4c), but confined to the Sri Lanka dome
[Vinayachandran and Yamagata, 1998]: the region occupied by the Sri Lanka bloom extents eastward of local upwelling (Figures $3 \mathrm{a}, 3 \mathrm{e}$, and $4 \mathrm{c}$ ). The combination of these two processes, horizontal advection by the Summer Monsoon Current and upwelling in the Sri Lanka dome, have also been suggested by Vinayachandran et al. [2004] on the basis of SLA and SST data to explain the bloom around Sri Lanka.

[55] In the Bay of Bengal, there was an indication in the physical model that the bloom in the North West region is due to upwelling (Figure 4c), and that this bloom is the equivalent of the bloom on the western coast of the Arabian Sea. Indeed, the Findlater jet also crosses the Bay of Bengal during the summer monsoon, and forces a similar pattern of vertical velocity to that in the Arabian Sea; that is, there is upwelling to the northwest and downwelling to the southeast. The bloom, however, was not as strong as in the Arabian Sea, owing to the much stronger stratification in the Bay of Bengal [Shetye and Gouveia, 1998]. On the other hand, the CIC signal seen in the Northern region of the Bay of Bengal was very likely to result from river outflows, which are particularly elevated during the rainy summer monsoon season: the location of the signal coincided with the mouth of the Brahmaputra and Ganga rivers.

[56] In the Southern Hemisphere, the bloom was located in a Tropical Band between $10^{\circ} \mathrm{S}$ and $17^{\circ} \mathrm{S}$ and overlaid the South Equatorial Current, which marks the border of the subtropical gyre (Figure 4a). On the northern side of the current (and of the Tropical Band), Ekman pumping is upward and the maximum MLD is rather shallow, while, on the southern side, Ekman pumping is downward and MLDs are much deeper [Woodbury et al., 1989; Périgaud and Delecluse, 1992; McCreary et al., 1993]. We hypothesize that the bloom in this Band is driven by nutrient transport, through upwelling in the north, and through vertical mixing in the south. Note that the southward extension of the Tropical Band bloom is limited compared with the southward extension of the deep MLDs region. This could reflect the bowl shape of the nitracline in the subtropical gyre, due to downward Ekman pumping: as we move southward away from the border of the gyre, the nitracline gets deeper and the nutrients are less likely to be entrained at the surface. We can also note that the bloom starts earlier on the northern side of the current, where Ekman pumping is upward. Kawamiya and Oschlies [2001] also point out that Rossby-wave-induced upwelling could be important in the northern part of the Tropical Band. Along the coast of Indonesia, the physical model indicates that the bloom is driven by upwelling (Figure 4c), as also suggested by Susanto and Marra [2005].

\subsection{Physical Driving Mechanisms of Winter Blooms}

[57] The strongest manifestation of the winter monsoon in terms of CIC was in the North Arabian Sea (Figure 3b). Previous observational reports of this event are given by Banse and McClain [1986], Banse and English [2000], Kumar et al. [2001], and Wiggert et al. [2002]. It is quite clear that the dominant physical driving mechanism is vertical mixing (Figure 4f) generated under the action of the cold, dry, continental northeasterly winds [Madhupratap et al., 1996; Lee et al., 2000]. Moreover, the reversal of winds during the winter monsoon is accompanied by downward Ekman pumping over most 
of the Arabian Sea (Figure 4d), which precludes upwelling-related mechanisms.

[58] Nevertheless, the exact causal relationship between vertical mixing and the occurrence of the bloom are not fully understood yet. Kumar et al. [2001] examined a 2-week time series in the northern Arabian Sea during the northeast monsoon and found a positive correlation between the depth of the mixed layer, the nutrient concentration, and the concentration of phytoplankton, suggesting that the bloom is provoked by the convective entrainment of nutrients at the base of the mixed layer. On the other hand, Wiggert et al. [2002], from a model study, suggested that the bloom intensity might not be controlled by the availability of nutrients, but rather by the nighttime penetration of diurnal mixing, which is controlled by the depth of the thermocline. This deep mixing acts as a daily dilution that prevents phytoplankton from fully developing during the next photo period.

[59] In our analysis, the eastern boundary of the North East Arabian Sea region coincided remarkably with that of the largest MLD gradient in the model (Figure 4f (white color) and Figure 3f). The correspondence between the MLD and CIC pattern did not hold on the western boundary of the North West Arabian Sea region. Moreover, the bloom started at the end of October in the east of the Arabian Sea and only in early January in the west. More precisely, in the North West Arabian Sea, the SCHL seasonal cycle exhibited a plateau from November to January (Figure $5 \mathrm{~g}$ ). These observations suggest that vertical mixing associated with the onset of the northeast monsoon drives a convective input of nutrients around November in the North Arabian Sea. In the eastern sector, this input translates into a phytoplankton bloom, while in the western sector, phytoplankton growth seems to be controlled by other processes.

[60] Two hypotheses can be put forward to explain the slower bloom dynamics in the western sector. First, it should be noted that the western Arabian Sea has experienced strong nutrient inputs and a strong bloom during the summer season. It is possible that the ecosystem is still functioning on regenerated production. Actually, there might a balance between growth and grazing following the summer monsoon. This balance could be destabilized by the deepening of the mixed layer in winter, or by phytoplankton advective inputs from the WICC, which is directed poleward and has a westward extension in the North Arabian Sea during the winter monsoon (Figure $4 \mathrm{~b}$ ) [Shetye et al., 1991]. Second, the thermocline is actually deeper in the western side of the Arabian Sea than in the eastern side. This is apparent both in our model (not shown) and in the model of Wiggert et al. [2002, Figure 3]. According to Wiggert et al. [2002], a deeper thermocline results in deeper nighttime convection and in a strong control on phytoplankton growth. The phytoplankton plateau of the North West Arabian Sea seasonal cycle might well be the consequence of a stronger light control in the west compared to the east, the difference being due to deeper nighttime convection. These are speculations, but they highlight that the North Arabian Sea bloom is yet not well understood and needs to receive greater attention in future analyses.

[61] The Bay of Bengal is also dominantly affected by downward Ekman pumping (Figure 4d). The MLD convec- tion pattern is similar to that of the Arabian Sea, although the intensity is much less (see also the MLD climatology of de Boyer Montégut et al. [2004]), because stratification caused by freshwater influx in stronger in the Bay of Bengal than in the Arabian Sea. The model reveals three spots of localized upwelling, one in the southwest to the east of Sri Lanka, the second along the northeast coast, and the third within the Malacca Strait region. These three spots coincide with the three winter bloom regions in the Bay of Bengal. In the South West Bay of Bengal, the bloom started in October and peaked in January (Figure 5j). Upwelling was restricted to the south of that region in the model, and there was a possible contribution from vertical mixing farther north (Figures $4 \mathrm{~d}$ and $4 \mathrm{f}$ ). This preponderance of Ekman pumping in driving this bloom was also suggested by Vinayachandran and Mathew [2003], who postulated that the bloom in the South West Bay of Bengal is nutrient-limited and that Ekman pumping, combined with a reduced stratification in the south of the Bay with respect to the north, is able to transport nutrients to the surface and thereby drive the bloom. They also mentioned the possible role of atmospheric cyclones, which are numerous in the region and which can mix water to deeper depths and thus induct an input of nutrients.

[62] In the North East Bay of Bengal, the mean seasonal cycle was very weak (Figure 5k), but as mentioned before, this weak variability on the regional scale hides a large variability at smaller scale that is entirely smoothed out by the averaging procedure. The bloom might be the result of upwelling, or due to river discharge, and a smaller-scale study would be needed to elucidate the processes.

[63] Finally, in the Malacca Strait region, the upwelling mechanism was also suggested by Tan et al. [2006] on the basis of wind-stress curl analysis. We believe that this region, characterized by its shallow topography, would also require a dedicated study.

[64] Regarding the bloom in the West Equatorial region (between $5^{\circ} \mathrm{S}$ and $5^{\circ} \mathrm{N}$ along the coast of Somalia), our model outputs suggest that it was driven by a strong upwelling located essentially to the north of the equator (Figure 4d). This bloom was well reproduced by the model of Wiggert et al. [2006], who attributed it to the decay of the southern gyre. In our analysis, there was some indication of a cyclonic geostrophic flow around the upwelling region, whose western arm coincided with the southward Somali Current (Figure 4b). We also observed a small time shift in the bloom timing north and south of the equator, with the bloom starting a couple of weeks later in the south; this time shift is indicative of advection of nutrients by the Somali Current, which is quite intense during this period $(0.1-$ $0.5 \mathrm{~m} \mathrm{~s}^{-1}$; Figure $4 \mathrm{~b}$ ), thus enabling this rapid transit.

[65] The bloom in the Madagascar region has been the subject of several studies and its origin is still an open question. Longhurst [2001] was the first to report this intermittent bloom to the east of Madagascar during February-April. He suggested that the bloom is due to changes in mixed-layer depth, modulated by the presence of eddies. Srokosz et al. [2004] offered the alternative hypothesis of a plankton wave, propagating from the coast to the open ocean. More recently, $U z$ [2007] suggests that this feature is driven by nitrogen fixation. With the present model, the bloom can be explained by upwelling along the coast of 
Madagascar, followed by transport by the retroflection of the South East Madagascar Current. In the Mozambique Channel, there is some indication of upwelling in the model that could explain the bloom. The observations of Weimerskirch et al. [2004] show intense mesoscale variability in the channel, not resolved by our analysis, that could also be the main factor driving nutrient inputs.

\section{Concluding Remarks}

[66] This paper presents a new type of analysis of SeaWiFS chlorophyll observations in the Indian Ocean and provides a basin-wide picture of the regional extent of the blooms. The method involves looking at the timing of the bloom onset and the cumulated increase in chlorophyll during the bloom. This method allows describing the complex bloom dynamics of the Indian Ocean, identifying variability patterns, defining specific bloom regions, and determining differences in timing and magnitude. This analysis is perfectly applicable to model outputs, and should be regarded as a new diagnostic to validate biophysical models: the two parameters as predicted by the model could be compared with the two parameters derived from observations.

[67] This study has delimited the boundaries of the major bloom regions in the Indian Ocean. This should facilitate the track design of oceanographic surveys. It should also provide a framework for the analysis of interannual variability.

[68] Our analysis highlights that, contrary to most parts of the world ocean, the biophysical provinces of the Indian Ocean vary tremendously from summer to winter. This is because the summer and winter monsoon winds drive distinct regional responses in the ocean.

[69] This study is one of the few using outputs from a physical OGCM to attempt to diagnose the physical factors driving the observed seasonal cycle of surface chlorophyll [see also Lévy et al., 2005]. It shows that OGCMs are accurate enough to colocate, in space and in time, the biological signal (the blooms) with the main dynamical factors likely to affect productivity, i.e., the surface currents, the vertical velocity, and the mixed-layer depth. This comparison stresses that the impact of the physical environment on biological processes can vary dramatically over relatively short distances.

[70] The determination of the mechanisms driving the blooms from this comparison is inevitably more speculative, given the fairly limited information. Nevertheless, at the latitudes of the Indian Ocean, where light never seriously limits photosynthesis, production is often limited by the availability of nutrients; in such a case, an examination of the physical fields provides a plausible view of the main pathway of nutrient supply. The main limitation of the method concerns the interpretation of the mixed-layer depth pattern, in the sense that mixed-layer deepening can either lead to increased or decreased phytoplankton biomass, but for different reasons: convective nutrient supply, dilution acting as irradiance limitation, dilution acting as a an escape from grazing. To gain further insight into the consequence of the change in mixed-layer depth, it would be helpful to examine the time shift between the change in mixed-layer depth and the change in chlorophyll; this is not possible with the time resolution of our climatology (of the order of 1 month), but should be feasible with data from individual years. Given these limitations, the method allows consideration of a certain number of mechanisms to explain the bloom patterns, and this attempt should be regarded as a road map for future research in the Indian Ocean basin.

[71] To end with, an interesting outcome of this study is that the signature of horizontal advection appears quite systematically as a gradient in the timing of the bloom. Whether this is due to the direct supply of nutrients, or of dissolved organic matter, or even of phytoplankton is still an open question. Work is in progress (V. Kone, personal communication, 2007) to address the uncertainties in the understanding of the blooms in the Indian Ocean that have been raised in this study with a coupled biophysical model.

[72] Acknowledgments. The visit of M. L., J. M. A., and F. D. to NIO was supported by IRD. This study was also supported by CNES, CNRS, and IFPREWAC. D. S. and S. S. C. S. were supported by grants from Department of Ocean Development, India. Programming of the algorithms for detecting the blooms make use of the IDL based SAXO package developed by Sebastien Masson and maintained with the help of Françoise Pinsard. We thank Olivier Aumont, Laure Resplandy, and Vamara Kone and for their careful reading of the manuscript and testing of the algorithms. Special thanks are owed to the Goddard GSFC/NASA for providing the SeaWiFS data, and to Carine Lesage for compiling them. We would particularly like to acknowledge the very constructive comments of two anonymous reviewers. This is NIO contribution 4282 .

\section{References}

Arnone, R. A., S. Ladner, P. E. La Violette, J. C. Brock, and P. A. Rochford (1998), Seasonal and interannual variability of surface photosynthetically available radiation in the Arabian Sea, J. Geophys. Res., 103, 77357748 .

Banse, K. (1987), Seasonality of phytoplankton chlorophyll in the central and northern Arabian Sea, Deep Sea Res., 34, 713-723.

Banse, K., and D. C. English (2000), Geographical differences in seasonality of CZCS-derived phytoplankton pigment in the Arabian Sea for 1978-1986, Deep Sea Res., Part II, 47, 1623-1677.

Banse, K., and C. R. McClain (1986), Winter blooms of phytoplankton in the Arabian Sea as observed by Coastal Zone Color Scanner, Mar. Ecol. Prog. Ser., 34, 201-211.

Banzon, V. F., R. E. Evans, H. R. Gordon, and R. M. Chomko (2004), SeaWiFS observations of the Arabian Sea southwest monsoon bloom for the year 2000, Deep Sea Res., Part II, 51, 189-208.

Bentamy, A., Y. Quilfen, F. Gobin, N. Grima, M. Lenaour, and J. Servain (1996), Determination and validation of average wind fields from ERS-1 scatterometer measurments, Global Atmos. Ocean Syst., 4, 1-29.

Brock, J. C., C. R. McClain, M. E. Luther, and W. W. Hay (1991), The phytoplankton bloom in the northwestern Arabian Sea during the SWM of 1979, J. Geophys. Res., 96, 20,623-20,642.

de Boyer Montégut, C., G. Madec, A. S. Fischer, A. Lazar, and D. Iudicone (2004), Mixed layer depth over the global ocean: An examination of profile data and a profile-based climatology, J. Geophys. Res., 109, C12003, doi:10.1029/2004JC002378.

de Boyer Montégut, C., J. Vialard, S. S. C. Shenoi, D. Shankar, F. Durand, C. Etheé, and G. Madec (2007), Simulated seasonal and interannual variability of the mixed layer heat budget in the northern Indian Ocean, J. Clim., 20, 3249-3268.

Dickey, T., J. Marra, D. E. Sigurdson, R. A. Weller, C. S. Kinkade, S. E. Zedler, J. D. Wiggert, and C. Langdon (1998), Seasonal variability of biooptical and physical properties in the Arabian Sea: October 1994-October 1995, Deep Sea Res., Part II, 45, 2001-2025.

Findlater, J. (1969), A major low-level air current near the Indian Ocean during the northern summer, Q. J. R. Meteorol. Soc., 95, 362-380.

Fischer, A. S., R. A. Weller, D. L. Rudnick, C. C. Eriksen, C. M. Lee, K. H. Brink, C. A. Fox, and R. R. Leben (2002), Mesoscale eddies, coastal upwelling, and the upper-ocean heat budget in the Arabian Sea, Deep Sea Res., Part II, 49, 2231-2264.

Flagg, C. N., and H.-S. Kim (1998), Upper ocean currents in the northern Arabian Sea from shipboard ADCP measurements collected during the 1994-1996 U.S. JGOFS and ONR programs, Deep Sea Res., Part II, 45, $1917-1959$

Hitchcock, G. L., E. L. Key, and J. Masters (2000), The fate of upwelled waters in the Great Whirl, August 1995, Deep Sea Res., Part II, 47, $1605-1621$. 
Kalnay, E., et al. (1997), The NCEP/NCAR 40-year reanalysis project, Bull. Am. Meteorol. Soc., 77, 437-471.

Kawamiya, M. (2001), Mechanism of offshore nutrient supply in the western Arabian Sea, J. Mar. Res., 59, 675-696.

Kawamiya, M., and A. Oschlies (2001), Formation of a basin-scale surface chlorophyll pattern by Rossby waves, Geophys. Res. Lett., 28, 4139-4142.

Kim, H.-S., C. N. Flagg, and S. D. Howden (2001), Northern Arabian Sea variability from TOPEX/Poseidon altimetry data: An extension of the US JGOFS/ONR shipboard ADCP study, Deep Sea Res., Part II, 48, 1069 1096.

Kumar, S. P., M. Madhupratap, M. Dileep Kumar, P. M. Muraleedharan, S. N. de Souza, M. Gauns, and V. V. S. S. Sarma (2001), High biological productivity in the central Arabian Sea during the summer monsoon driven by Ekman pumping and lateral advection, Curr. Sci., 81, 16331638.

Lee, C. M., B. H. Jones, K. H. Brink, and A. S. Fischer (2000), The upperocean response to monsoonal forcing in the Arabian Sea: Seasonal and spatial variability, Deep Sea Res., Part II, 47, 1177-1226.

Lévy, M., Y. Lehahn, J.-M. André, L. Memery, H. Loisel, and E. Heifetz (2005), Production regimes in the northeast Atlantic: A study based on Sea-viewing Wide Field-of-view Sensor (SeaWiFS) chlorophyll and OGCM mixed-layer depth, J. Geophys. Res., 110, C07S10, doi:10.1029/2004JC002771.

Lévy, M., J.-M. André, D. Shankar, F. Durand, and S. S. C. Shenoi (2006), A quantitative method for describing the seasonal cycles of surface chlorophyll in the Indian Ocean, in Remote Sensing of the Marine Environment, edited by R. J. Frouin et al., Proc. SPIE Int. Soc. Opt. Eng., 6406, 8 pp.

Lierheimer, L. J., and K. Banse (2002), Seasonal and interannual variability of phytoplankton pigment in the Laccadive (Lakshadweep) Sea as observed by the Coastal Zone Color Scanner, Proc. Indian Acad. Sci., Earth Planet. Sci., 111, 163-185.

Longhurst, A. R. (2001), A major seasonal phytoplankton bloom in the Madagascar Basin, Deep Sea Res., Part I, 48, 2413.

Madhupratap, M., S. P. Kumar, P. M. A. Bhattathiri, M. D. Kumar, S. Raghukumar, K. K. C. Nair, and N. Ramaiah (1996), Mechanism of the biological response to winter cooling in the northeastern Arabian Sea, Nature, 384, 549-552.

Manghnani, V., J. M. Morrison, T. S. Hopkins, and E. Böhm (1998), Advection of upwelled waters in the form of filaments off Oman during the southwest monsoon, Deep Sea Res., Part II, 45, 2027-2052.

Marra, J., and D. Barber (2005), Primary production in the Arabian Sea: A synthesis of JGOFS data, Prog. Oceanogr., 65, 159-175.

McCreary, J. P., P. K. Kundu, and R. L. Molinari (1993), A numerical investigation of the dynamics, thermodynamics, and mixed-layer processes in the Indian Ocean, Prog. Oceanogr., 31, 181-244.

McCreary, J. P., Jr., K. E. Kohler, R. R. Hood, and D. B. Olson (1996), A four-component ecosystem model of biological activity in the Arabian Sea, Prog. Oceanogr., 37, 193-240.

Murtugudde, R. G., S. R. Signorini, J. R. Christian, A. J. Busalacchi, C. R. McClain, and J. Picaut (1999), Ocean color variability of the tropical Indo-Pacific basin observed by SeaWiFS during 1997-1998, J. Geophys. Res., 104, 18,351-18,366.

Périgaud, C., and P. Delecluse (1992), Annual sea level variations in the southern tropical Indian Ocean from GEOSAT and shallow-water simulations, J. Geophys. Res., 97, 20,169-20,178.

Schott, F., and J. P. McCreary (2001), The monsoon circulation of the Indian Ocean, Prog. Oceanogr., 51, 1-123.

Shankar, D. (1998), Low-frequency variability of sea level along the coast of India, Ph.D. thesis, Goa Univ., Goa, India.

Shankar, D., and S. R. Shetye (1997), On the dynamics of the Lakshadweep High and Low in the southeastern Arabian Sea, J. Geophys. Res., 102, $12,551-12,562$

Shankar, D., P. N. Vinayachandran, and A. S. Unnikrishnan (2002), The monsoon currents in the north Indian Ocean, Prog. Oceanogr., 52, $63-$ 120.

Shankar, D., V. V. Gopalakrishna, S. S. C. Shenoi, F. Durand, S. R. Shetye, C. K. Rajan, Z. Johnson, N. Araligidad, and G. S. Michael (2004), Observational evidence for westward propagation of temperature inversions in the southeastern Arabian Sea, Geophys. Res. Lett., 31, L08305, doi:10.1029/2004GL019652.

Shetye, S. R., and A. D. Gouveia (1998), The Sea, vol. 11, The Global Coastal Ocean: Regional Studies and Syntheses, edited by A. R. Robinson and K. H. Brink, John Wiley, Hoboken, N. J.
Shetye, S. R., A. D. Gouveia, S. S. C. Shenoi, D. Sundar, G. S. Michael, A. M. Almeida, and K. Santanam (1990), Hydrography and circulation off the west coast of India during the Southwest Monsoon 1987, J. Mar. Res., 48, 359-378.

Shetye, S. R., A. D. Gouveia, S. S. C. Shenoi, G. S. Michael, D. Sundar, A. M. Almeida, and K. Santanam (1991), The coastal current off western India during the northeast monsoon, Deep Sea Res., 38, 1517-1529.

Srokosz, M. A., G. D. Quartly, and J. J. H. Buck (2004), A possible plankton wave in the Indian Ocean, Geophys. Res. Lett., 31, L13301, doi:10.1029/2004GL019738.

Susanto, R. D., and J. Marra (2005), Effect of the 1997/98 El Niño on chlorophyll $a$ variability along the coasts of Java and Sumatra, Prog. Oceanogr., 18, 124-127.

Tan, C. K., J. Ishizaka, S. Matsumara, F. M. Yusoff, and I. H. Mohamaed (2006), Seasonal variability of SeaWiFS chlorophyll $a$ in the Malacca Straits in relation to Asian monsoon, Cont. Shelf Res., 26, 168-178.

U.N. Educational, Scientific and Cultural Organization (Ed.) (1996), Discharge of Selected Rivers of the World, vol., II Part II, UNESCO Publishing, Paris.

Uz, B. M. (2007), What causes the sporadic phytoplankton bloom southeast of Madagascar?, J. Geophys. Res., 112, C09010, doi:10.1029/ 2006JC003685.

Vinayachandran, P. N., and S. Mathew (2003), Phytoplankton bloom in the Bay of Bengal during the northeast monsoon and its intensification by cyclones, Geophys. Res. Lett., 30(11), 1572, doi:10.1029/ 2002GL016717.

Vinayachandran, P. N., and T. Yamagata (1998), Monsoon response of the sea around Sri Lanka: Generation of thermal domes and anticyclonic vortices, J. Phys. Oceanogr., 28, 1946-1960.

Vinayachandran, P. N., P. Chauhan, and S. R. Nayak (2004), Biological response of the sea around Sri Lanka to summer monsoon, Geophys. Res. Lett., 31, L01302, doi:10.1029/2003GL018533.

Weimerskirch, H., M. Le Corre, S. Jaquemet, M. Potier, and F. Marsac (2004), Foraging strategy of a top predator in tropical waters: Great frigatebirds in the Mozambique Channel, Mar. Ecol. Prog. Ser., 14, $297-308$

Weller, R. A., A. S. Fischer, D. L. Rudnick, C. C. Eriksen, T. D. Dickey, J. Marra, C. Fox, and R. Leben (2002), Moored observations of upperocean response to the monsoons in the Arabian Sea during 1994-1995, Deep Sea Res., Part II, 49, 2195-2230.

Wiggert, J. D., R. G. Murtugudde, and C. R. McClain (2002), Processes controlling interannual variations in wintertime (Northeast Monsoon) primary production in the central Arabian Sea, Deep Sea Res., Part II, 49, 2319-2343

Wiggert, J. D., R. R. Hodd, K. Banse, and J. C. Kindle (2005), Monsoondriven biogeochemical processes in the Arabian Sea, Prog. Oceanogr., $65,176-213$.

Wiggert, J. D., R. G. Murtugudde, and J. R. Christian (2006), Annual ecosystem variability in the tropical Indian Ocean: Results of a coupled bio-physical ocean general circulation model, Deep Sea Res., Part II, 53, 644-676.

Woodbury, K. E., M. E. Luther, and J. J. O'Brien (1989), The wind-driven seasonal circulation in the southern tropical Indian Ocean, J. Geophys. Res., 94, 17,985-18,002.

Xie, P., and P. Arkin (1997), Analyses of global monthly precipitation using gauge observations, satellite estimates and numerical model predictions, J. Clim., 9, 840-858

Young, D. K., and J. C. Kindle (1994), Physical processes affecting availability of dissolved silicate for diatom production in the Arabian Sea, J. Geophys. Res., 99, 22,619-22,632.

J.-M. André and M. Lévy, LOCEAN-IPSL, Université Pierre et Marie Curie, BC100, 4 Place Jussieu, F-75252 Paris Cedex 05, France. (andre@1ocean-ipsl.upmc.fr; marina@locean-ipsl.upmc.fr)

C. de Boyer Montégut, Frontier Research Center for Global Change, JAMSTEC, 3175-25 Showamachi Kanazawa-ku, Yokohama, Kanagawa 236-0001, Japan. (clement@jamstec.go.jp)

F. Durand, LEGOS, IRD, 14 Avenue E. Belin, F-31400 Toulouse, France. (fabien.durand@ird.fr)

D. Shankar and S. S. C. Shenoi, Physical Oceanography Division, National Institute of Oceanography, Dona Paula, Goa 403004, India. (shankar@nio.org; shenoi@nio.org) 